\title{
SOI Back Reflectors for Tb Doped Oxide Electroluminescent Devices
}

\author{
By
}

Harjinder Singh Saini, B. Tech.

\begin{abstract}
A thesis submitted to
The Faculty of Graduate and Postdoctoral Affairs

in partial fulfillment of

the requirements for the degree of

Master of Applied Science

in Electrical and Computer Engineering

Ottawa-Carleton Institute for

Electrical and Computer Engineering
\end{abstract}

\begin{abstract}
Department of Electronics
Faculty of Engineering

Carleton University

Ottawa, Ontario, Canada
\end{abstract}

September 2011

Copyright (C)

2011 - Harjinder Singh Saini 
Library and Archives

Canada

Published Heritage

Branch

395 Wellington Street

Ottawa ON K1A ON4

Canada
Bibliothèque et

Archives Canada

Direction du

Patrimoine de l'édition

395 , rue Wellington

Ottawa ON K1A ON4

Canada
Yourfile Votre référence

ISBN: 978-0-494-83068-0

Our file Notre référence

ISBN: 978-0-494-83068-0

NOTICE:

AVIS:

The author has granted a nonexclusive license allowing Library and Archives Canada to reproduce, publish, archive, preserve, conserve, communicate to the public by telecommunication or on the Internet, loan, distribute and sell theses worldwide, for commercial or noncommercial purposes, in microform, paper, electronic and/or any other formats.

The author retains copyright ownership and moral rights in this thesis. Neither the thesis nor substantial extracts from it may be printed or otherwise reproduced without the author's permission.

L'auteur a accordé une licence non exclusive permettant à la Bibliothèque et Archives Canada de reproduire, publier, archiver, sauvegarder, conserver, transmettre au public par télécommunication ou par l'Internet, prêter, distribuer et vendre des thèses partout dans le monde, à des fins commerciales ou autres, sur support microforme, papier, électronique et/ou autres formats.

L'auteur conserve la propriété du droit d'auteur et des droits moraux qui protège cette thèse. $\mathrm{Ni}$ la thèse ni des extraits substantiels de celle-ci ne doivent être imprimés ou autrement reproduits sans son autorisation.
In compliance with the Canadian Privacy Act some supporting forms may have been removed from this thesis.

While these forms may be included in the document page count, their removal does not represent any loss of content from the thesis.
Conformément à la loi canadienne sur la protection de la vie privée, quelques formulaires secondaires ont été enlevés de cette thèse.

Bien que ces formulaires aient inclus dans la pagination, il n'y aura aucun contenu manquant.

\section{Canadä}




\section{Abstract}

Electroluminescent devices based on light emission from $\mathrm{Tb}$-doped $\mathrm{SiO}_{2}$ incorporated in a MOS capacitor structure have been formed on SOI substrates. It is shown that with appropriate choice of Si film and buried oxide thickness the SOI substrate can serve as a quarter-wave high-low-high index back reflector. Analysis predicts this back reflector can boost total light output integrated over the $\mathrm{Tb}$ emission spectrum by approximately $35 \%$ compared to a bulk substrate control device. Experimental devices using $100 \mathrm{~nm}$ thick PECVD $\mathrm{SiO}_{2}$ emitting layers doped with $1 \% \mathrm{~Tb}$ were fabricated on substrates with nominal 32 and $108 \mathrm{~nm}$ Si film thicknesses (corresponding to approximately $\lambda / 4$ and $3 \lambda / 4$ at the $\mathrm{Tb}$ emission peak). The $\mathrm{Si}$ films were doped to $10^{19}-10^{20} \mathrm{~cm}^{-3}$ by As implantation. Uniform bright green electroluminescence was obtained from $250 \mu \mathrm{m}$ square devices, demonstrating that current crowding is not an issue even with such a thin

Si film. The comparison of output spectra for thick and thin Si films demonstrates that optical absorption in the heavily doped Si film does not seriously degrade the light output of the devices. 


\section{Acknowledgements}

I would like to thank my supervisor, Dr. Garry Tarr who provided the initial inspiration for this work and gave critical guidance throughout the process. His solid understanding of the subject and mentorship helped me grow and mature as a serious graduate researcher and made this thesis an enjoyable experience.

I thank Carol Adams, Rob Vandusen, Angela Burns and Rick Adams for all of their help in preparing my samples in the Carleton University Microfabrication Facility.

I would also like to thank P. Mascher at Department of Engineering Physics, McMaster University, Hamilton for arranging the Tb deposition on the samples and T.W. MacElwee at Group IV Semiconductor, Ottawa, Ontario, Canada for providing access to his Testing Laboratory, for his advice and suggestions throughout the project. A special thanks to A. Rankin for his support and healthy suggestions throughout this project.

I would like to acknowledge and thank my colleagues, N. Fong, Shuxia Li, M.Sandhu and A.M. Miles for the friendly, often philosophical, discussions which made me laugh and kept me engaged. I would also like to express my gratitude to the professors, staff and students at the department of electronics for making my work an enjoyable experience.

Finally, I thank my parents Harbinder Singh Saini and Jaswant Kaur Saini, and my sisters Daljeet and Rajwinder for their years of patience. They inculcated in me, the 
determination and dedication to do whatever I undertake well. I am grateful to you for your love and support throughout this thesis. 


\section{Table of Contents}

$\begin{array}{ll}\text { Abstract } & \text { iii }\end{array}$

Acknowledgements iv

Table of Contents $\quad$ vi

List of Tables $\quad$ viii

$\begin{array}{ll}\text { List of Figures } & \text { ix }\end{array}$

List of Abbreviations and Acronyms $\quad$ xi

$\begin{array}{ll}\text { Chapter } 1 \text { Introduction } & 1\end{array}$

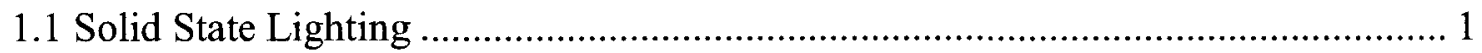

1.2 Silicon Based Light Emitting Devices........................................................... 2

1.3 Use of SOI Wafer as Back Reflector ........................................................... 3

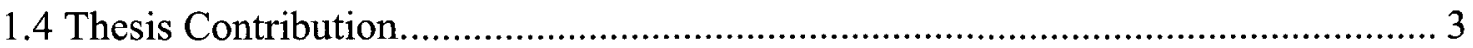

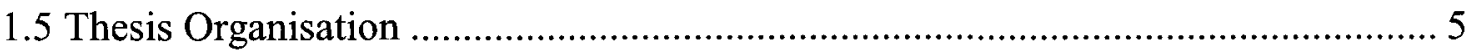

$\begin{array}{lr}\text { Chapter } 2 \text { Background } & 6\end{array}$

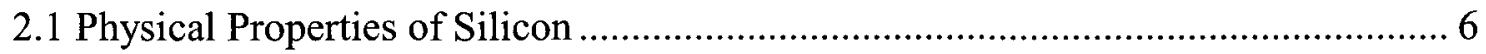

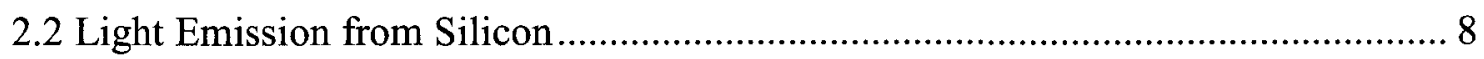

2.3 Luminescence via Impurity Centres- Doping of Silicon with Rare Earth Metals .... 8

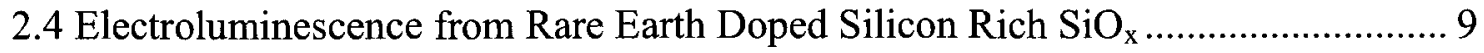

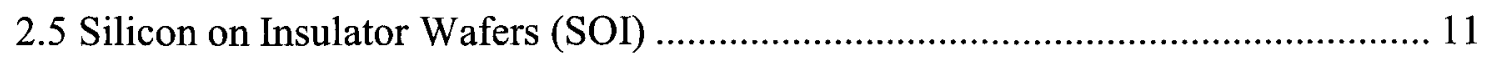

2.5.1 SIMOX (Separation by Implanted Oxygen) ...................................... 11 
2.5.2 BESOI (Bond and Etch-back SOI) ............................................................. 12

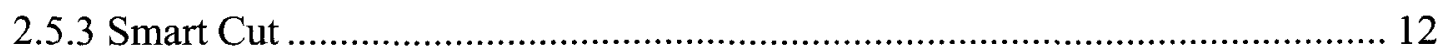

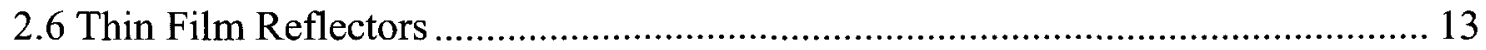

$\begin{array}{lr}\text { Chapter } 3 \text { Theory and Modeling } & 15\end{array}$

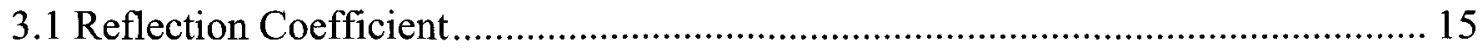

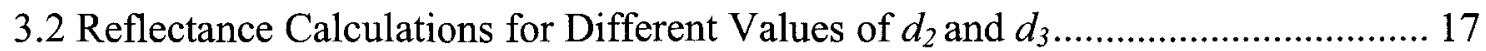

3.3 Optical Absorption in Si Film....................................................................... 19

3.4 Reflection Coefficient Calculations Based On the Wafer Available In Carleton University Fabrication Lab .................................................................................. 21

3.5 Comparison of Light Output Using SOI Wafer and Bulk Substrate. ..................... 22

$\begin{array}{lr}\text { Chapter } 4 \text { Device Fabrication } & 24\end{array}$

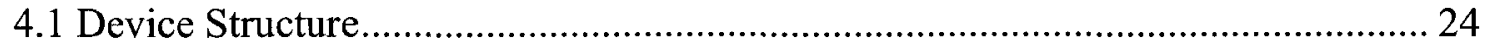

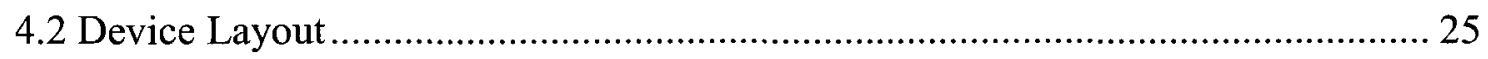

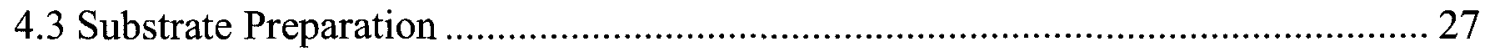

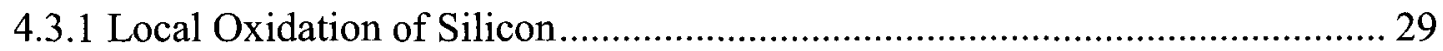

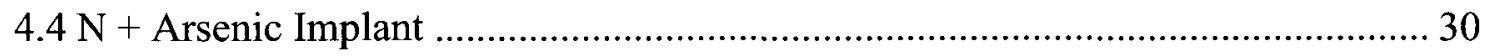

4.5 Emitter Dielectric Deposition ........................................................................... 35

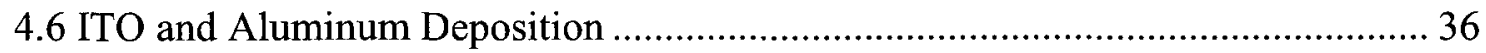

$\begin{array}{ll}\text { Chapter } 5 \text { : Optical Testing and Discussion } & 37\end{array}$

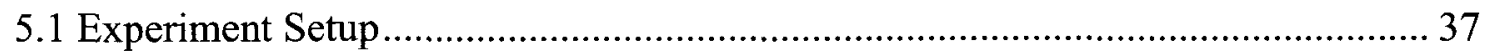

Chapter 6 Results: Conclusion and Discussion $\quad 44$

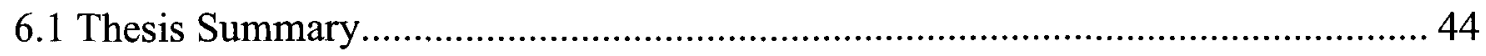

6.2 Recommendations for Future Work .................................................................... 45

Appendix A - Fabrication Run Sheet $\quad 46$

$\begin{array}{lr}\text { REFERENCES } & 56\end{array}$ 


\section{List of Tables}

Table 3.1 Refractive indices $\mathrm{n}$ for $\mathrm{Si}$ and $\mathrm{SiO}_{2}$ at $\lambda=545 \mathrm{~nm}$ (Tb emission peak)[38] .. 18

Table 3.2 Parameters of the SOI wafers used in the project............................................ 21

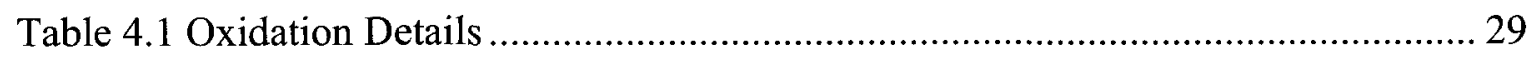

Table 5.1 Ratio of 545 to $495 \mathrm{~nm}$ peak height for different samples. ............................. 43 


\section{List of Figures}

Figure 2.1 Schematic of energy as a function of momentum graph for an indirect bandgap in semiconductors

Figure 2.2 $\mathrm{Tb}$-doped oxide electroluminescent device structure on bulk silicon 10

Figure 3.1 Structure for optical modeling of electroluminescent devices .....

Figure 3.2 Normalized emission spectrum for Tb-doped $\mathrm{SiO}_{2}$ [39]

Figure 3.3 Power reflectance versus wavelength for optimum $(\lambda / 4) \mathrm{Si}$ film and buried oxide thickness.

Figure 3.4 Power reflectance versus wavelength for $(\lambda / 4)$ Si film and $1006 \mathrm{~nm}$ buried oxide thickness

Figure 3.5 Predicted output spectrum for $\lambda / 4$ Si film thickness over $1006 \mathrm{~nm}$ buried oxide. 23

Figure 4.1 : Tb-doped oxide electroluminescent device structure on SOI. 25

Figure 4.2: Overall layout of the SOI Electroluminescent devices. 26

Figure 4.3 Layout for a typical $250 \mu \mathrm{m}$ square device 27

Figure 4.4 Suprem4 simulation of doping profile on thick silicon with low doping....... 31

Figure 4.5 Suprem4 simulation of doping profile on thick Silicon with high doping..... 32 Figure 4.6 Suprem4 simulation of doping profile on thick silicon with low doping after annealing....

Figure 4.6 Suprem4 simulation of doping profile on thick silicon with high doping after annealing. 34

Figure 5.1 Typical I-V curve of test device. 38

Figure 5.2 Picture of failed device 39

Figure 5.3 shows the test setup at Group IV semiconductor, Kanata...... 40

Figure 5.4 Output spectra under photoexcitation (arbitrary units on y-axis)..... 
Figure 5.5 Comparison of output spectra for thick and thin Si films on the same chip (arbitrary units on y-axis) 


\section{List of Abbreviations and Acronyms}

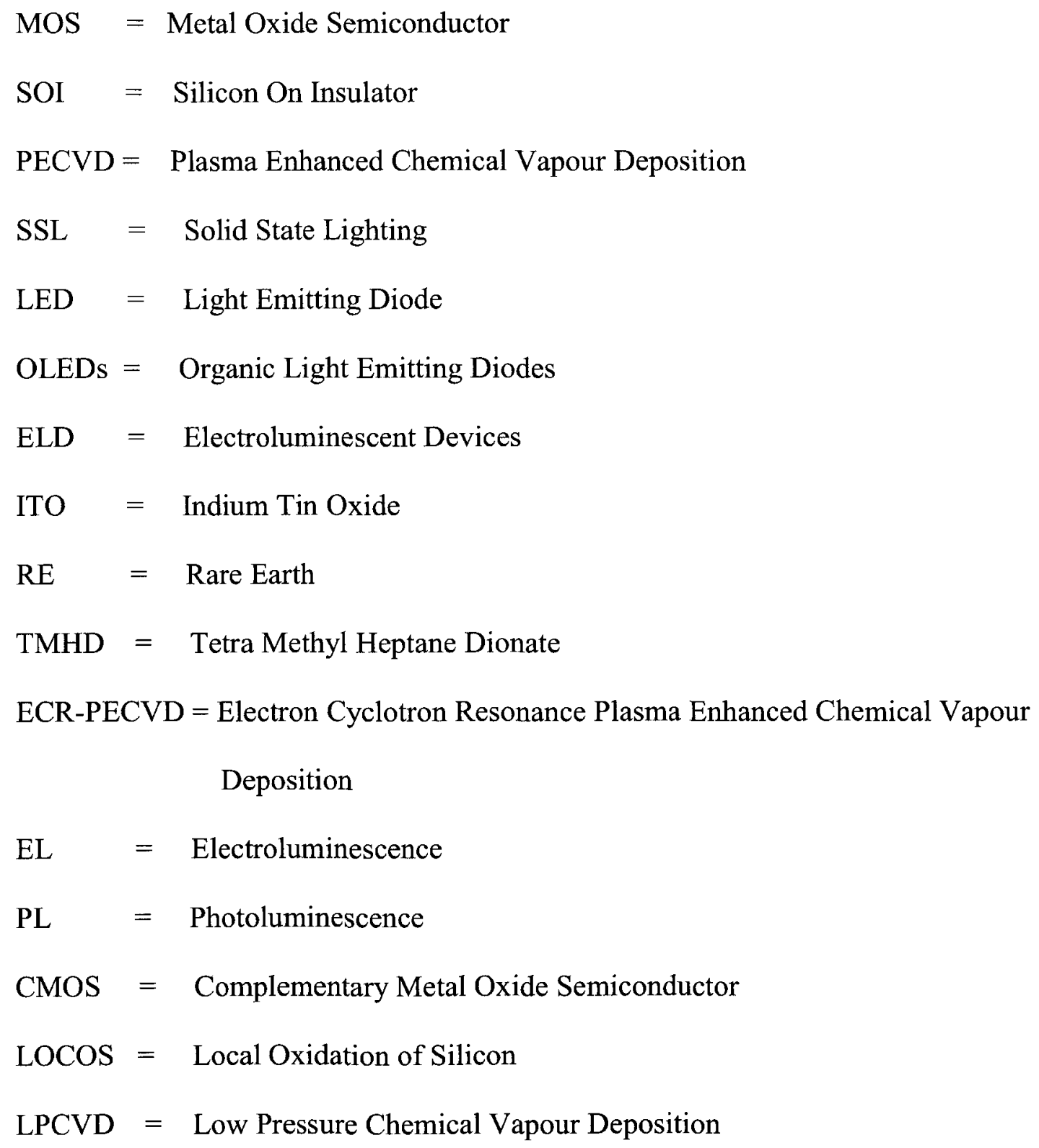




\section{Chapter 1 Introduction}

\subsection{Solid State Lighting}

People on earth have made tremendous progress in the field of science and technology over the last century or so, but we all have to pay a huge price for it. Rapid industrialization has impacted our climate to a large extent and all the developing as well as the developed nations are therefore seeking ways to reduce their energy loss and consumption [1]. SSL is being considered as an important step to conserve electrical energy, thereby reducing greenhouse gas emissions. It has been estimated that worldwide lighting is responsible for approximately 1900 mega tonne $\mathrm{CO}_{2}$ emissions [2].

Lighting applications that use light-emitting diodes (LEDs), organic light-emitting diodes (OLEDs), or light-emitting polymers are commonly referred to as solid-state lighting [3]. SSL technology helps in conservation of electrical energy as it is much more efficient as compared to standard incandescent lamps and somewhat more efficient than fluorescent lights [4]. Most SSL technologies do not require toxic materials, while conventional fluorescent lights contain significant amounts of mercury [5]. The energy savings potential of SSL technology is enormous. For example, it has been estimated that with the use of LEDs in traffic signals alone, the United States could save $2.5 \mathrm{GWh}$ annually [6]. Globally, it has been estimated that converting to SSL technology wherever 
possible could save $860 \mathrm{TWh}$ and eliminate 200 million tonnes of carbon dioxide emission annually worldwide [7].

\subsection{Silicon Based Light Emitting Devices}

Silicon microelectronic devices have revolutionized society and the global economy. Today there is a major research effort around the globe to try and repeat the success story of silicon microelectronics in the photonics area [8]. Much of this research is focused on using silicon in light emitters. The push to use silicon to produce light is based on two main factors. First, optoelectronics has emerged as a major industry in its own right and there is a strong and continuing desire to integrate optical devices such as lasers and detectors, and optical modulators, multiplexers, waveguides and interconnects within the established microelectronics industry. Group III-V semiconductors such as GaAs have optical properties ideal for these devices. So a lot of work is carried out on these semiconductors but due to the huge existing investment in silicon based technology, there is a great desire to use silicon material for such devices. Silicon, being an indirect bandgap semiconductor, it has weak light emission, which is considered a major drawback [9]. There are number of ways to overcome this drawback such as nanocrystalline silicon, Er doped silicon, metal-oxide-semiconductor (MOS) structure with native oxide, porous silicon based devices, polymer deposition in silicon substrates, $\mathrm{Si}^{+}$-implanted $\mathrm{SiO}_{2}, \mathrm{GaN}$ growth on silicon substrates and so on [10]. GroupIV Semiconductor based in Kanata, Ontario, Canada has made considerable progress in obtaining efficient, bright EL from rare earth doped oxides on silicon. 


\subsection{Use of SOI Wafer as Back Reflector}

SOI wafers are finding widespread application in photonics and microelectronics. Due to its easy availability and excellent optical and electronic performances SOI has received more and more attention in recent years [11]. In SOI wafers, a uniform layer of silicon dioxide is sandwiched between a thick silicon substrate and a thin surface layer of crystalline silicon [12]. As Si has a refractive index of 4.1 which is much higher than $\mathrm{SiO}_{2}$, so SOI makes a stack of material with High-Low-High refractive index which is ideal to get maximum reflection of visible light. This makes SOI a suitable material for use as a back reflector to maximize light emission from silicon devices. Some results on the use of SOI back reflectors for nanostructured $\mathrm{Si}$ emitters have been reported previously by Bogalecki et al [13].

\subsection{Thesis Contribution.}

This thesis demonstrates the use of SOI substrates to increase the light emission efficiency of ELDs produced by Group IV Semiconductor. The present generation of devices produced by Group IV are fabricated on bulk Si substrates. Half of the light emitted in the doped oxide travels towards the substrate. Simple theory [13] predicts that only $60 \%$ of the light directed towards the substrate is reflected. The remainder of the light enters the substrate and is lost to absorption. In order to increase the light output here SOI wafers are used in place of bulk Si substrates. SOI substrate acts as a back reflector thereby increasing the light output of the devices. The Tb-doped light emitting oxides produced by Group IV Semiconductor have a peak emission at $545 \mathrm{~nm}$. In order to get the maximum reflection out of the SOI wafer at $545 \mathrm{~nm}$ wavelength, the silicon film 
and buried oxide thicknesses should both be an odd integer multiple of a quarter wavelength. A $\lambda / 4 \mathrm{Si}$ film corresponds to a physical thickness of $32 \mathrm{~nm}$. The reflectance is integrated across the $\mathrm{Tb}$ emission spectrum to determine the total theoretically possible boost in optical output provided by the back reflector. Experimental devices were fabricated to test the back reflector concept. SOITEC Smart Cut SOI wafers with silicon thickness of $340 \mathrm{~nm}$ and buried oxide thickness of $1 \mu \mathrm{m}$ were used and by successive oxidation the silicon film was thinned down to $32 \mathrm{~nm}$ [14]. Tb doped $\mathrm{SiO}_{2}$ was deposited on the SOI wafers and then an ITO contact was made on the top. ITO is semi transparent and acts as a conductor in the device. Al metal was used to make final contact to the thin silicon film and the ITO. Electrical as well as optical testing of the devices was performed at Carleton University and at Group IV Semiconductor Kanata. It was established that SOI substrates can indeed be used to make electroluminescent MOS devices and these substrates act as a back reflector. 


\subsection{Thesis Organisation}

This thesis has been divided into six chapters:

Chapter 1 has provided the motivation of the thesis, importance of SSL technology in today's world, brief overview of $\mathrm{Si}$ based ELDs, thesis contribution and thesis organisation.

Chapter 2 provides a background and review of previous literature for the project.

Chapter 3 describes theory and modelling of experimental devices.

Chapter 4 discusses fabrication of experimental samples.

Chapter 5 describes the electrical and optical testing of the experimental devices.

Chapter 6 gives conclusions and recommendations for further work. 


\section{Chapter 2 Background}

In this chapter a detailed background of silicon light emitters is provided. This chapter begins with a brief explanation of the physical properties of silicon relevant to light emission, outlines different methods to obtain light emission from silicon despite the indirect band gap, summarizes the properties of SOI and describes reflection from thin film stacks.

\subsection{Physical Properties of Silicon}

The optical as well as the electrical properties of semiconductors are determined by their energy-band structure. The band structure relates the energy and crystal momentum (or wave vector) of electrons moving in the crystal. During the energy conversion process (electrical to optical and vice versa) electrons move from conduction band to valence band and vice versa. During the transition of electrons from valence band to conduction band and vice versa, momentum as well as energy has to be conserved [16]. Conservation of momentum cannot be achieved in indirect semiconductors unless a phonon is involved in the transition (in other words, momentum exchange with the lattice is required). Silicon has an indirect bandgap i.e. minimum of conduction band is not directly above the maximum of valence band. Transfer of an electron from the conduction band to the valence band through the emission of a photon therefore does not conserve momentum 
and is not an allowed process [17]. A phonon must be involved in the process to conserve momentum, which greatly reduces the probability of the process (leading to long minority carrier lifetimes in silicon). Normally the energy released in the transition is imparted to the phonon, and no photon is emitted. Silicon light emission efficiency is therefore very low due to the indirect bandgap. Indirect bandgap is shown in Figure 2.1. Different ways to overcome this are being explored by various researchers.

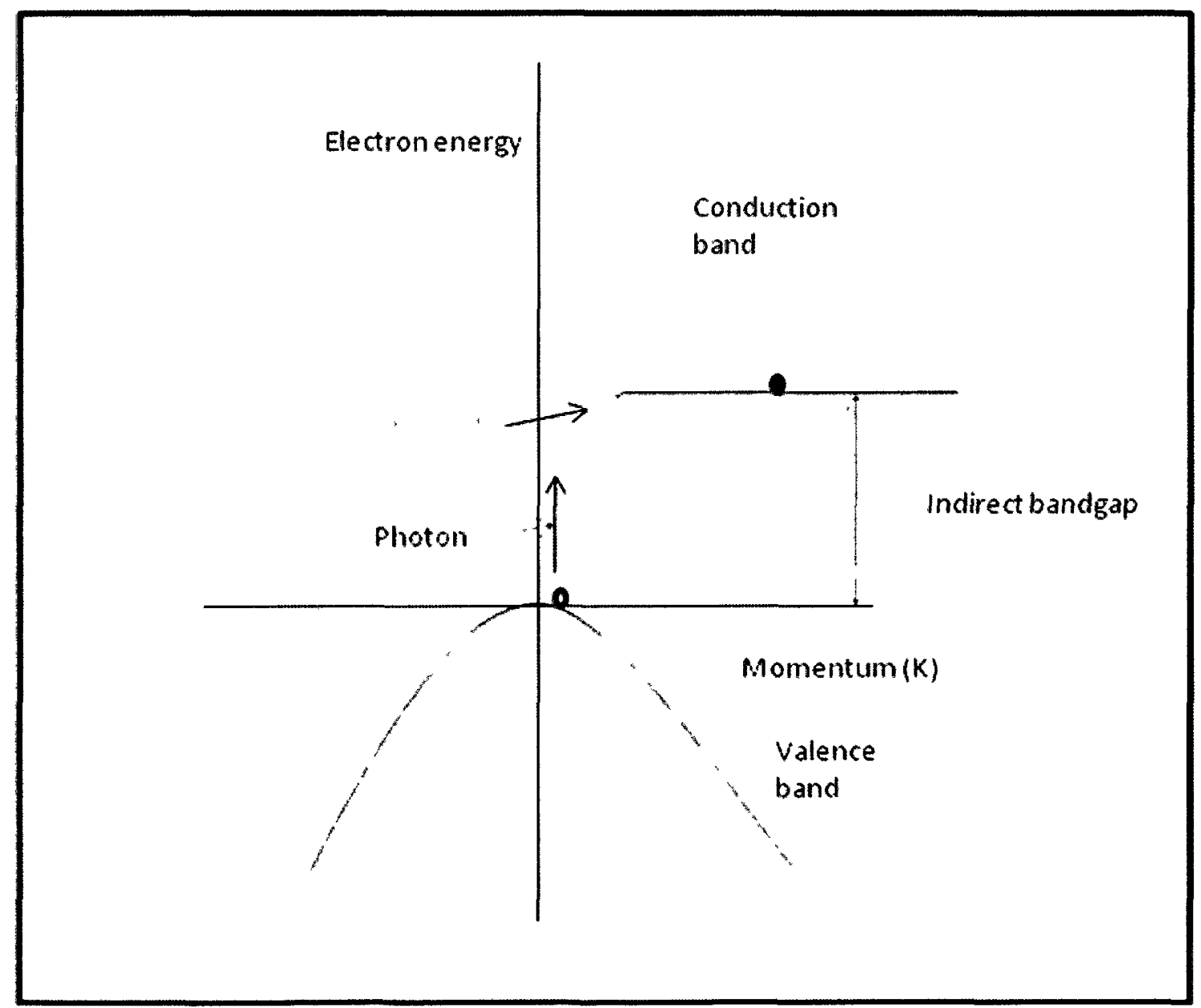

Figure 2.1 Schematic of energy as a function of momentum graph for an indirect bandgap in semiconductors. 


\subsection{Light Emission from Silicon}

In order to increase the light emission efficiency of silicon, the indirect bandgap has to be overcome [18][19]. Lockwood [20] has extensively reviewed the various methods that are being explored to accomplish this. The main methods under investigation are listed below.

1. Band structure engineering via alloying[21]

2. Luminescence via impurity centres[22][23]

3. Silicon nanostructures- Porous Silicon, silicon nanoclusters, quantum wells, wires and dots.[24][25]

4. Polymers and molecules containing silicon

5. Hybrid methods for integrating direct gap materials with silicon[26][27]

In this thesis we will focus on approach 2 to create light emission, relying on rare earth impurities to emit light from silicon-based devices.

\subsection{Luminescence via Impurity Centres- Doping of Silicon with Rare Earth Metals}

Doping of silicon with rare-earth elements such as $\mathrm{Er}, \mathrm{Gd}, \mathrm{Tb}, \mathrm{Ce}$ and $\mathrm{Eu}$ is being investigated to generate light in the infrared spectral range. Of these Er has been the most intensively investigated [28][29]. As Er emits light at the same wavelength independently of the host, it has got a number of advantages over other Si based light emitters. Through various experiments it has been observed that solid solubility of Er is few orders of 
magnitude less than the concentration needed for the LEDs [30]. There are several ways by which Er can be incorporated into silicon such as ion implantation, solid phase epitaxy (SPE), molecular beam epitaxy (MBE), chemical vapour deposition (CVD) and ion beam epitaxy (IBE).

A wide variety of interesting properties are shown by RE atoms. They have an unoccupied core shell of electrons (the $4 \mathrm{f}$ shell) in the interior of the atom. These inner electrons are unaffected by the ion's exterior surroundings due to the shielding effect of the outer electrons. Intra-4f transitions occur in trivalent Er atoms implanted in semiconductor or dielectric materials having an incomplete $4 \mathrm{f}$ electronic shell when energized by an optical source. During the implantation the silicon lattice is damaged. Thermal treatment is used to repair this damage and activate charged erbium ions.

\subsection{Electroluminescence from Rare Earth Doped Silicon Rich $\mathrm{SiO}_{\mathbf{x}}$}

Group IV Semiconductor Inc of Ottawa, Ontario has developed light emitters using RE doped silicon rich $\mathrm{SiO}_{\mathrm{x}}$. The basic structure of the ELDs made by Group IV is illustrated in Fig. 2.2. The devices are made on a heavily doped bulk n-type silicon substrate. The light emitting layer consists of a rare earth doped silicon-rich silicon oxide film deposited by ECR-PECVD [31]. The top contact to the device is made with a layer of transparent conductor (typically (ITO)). All of the Er-doped films were deposited from $\mathrm{SiH}_{4}, \mathrm{O}_{2}$ and Er $(\mathrm{TMHD})_{3}$. Wafers were annealed at high temperatures in flowing argon. Front and back sides of the wafer were provided with metal contacts made of Aluminum. Tb doped layers were deposited in slightly different way as compared to Er doped layers. The same procedure was followed to deposit $\mathrm{Tb}$ as used for Er deposition with few changes. The 
ECR-PECVD system used for Tb doping was slightly different, with a higher thickness and lower rare earth concentration.

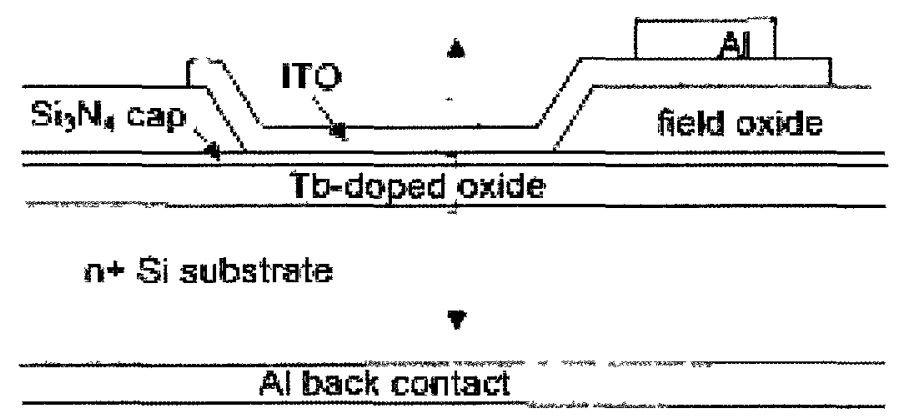

Figure 2.2 Tb-doped oxide electroluminescent device structure on bulk silicon

DC bias was applied to the films while keeping the current densities below $100 \mathrm{~mA} / \mathrm{cm}^{2}$ before breakdown. It was observed that with DC bias, an increase in electric field and charge trapping in the oxide led to breakdown of the device. In order to operate the device at high current densities and high electric fields, AC bias with a sinusoidal drive frequency of $15 \mathrm{kHz}$ was applied. ITO interface or substrate can be used to inject electrons for SRSO films to conduct. It was assumed that AC bias reduces the overall effect of the trapped oxide charge. The EL spectra obtained from Tb doped devices is shown in Figure 3.2 [31]. It has been reported that Er doped samples have a double peak at $535 / 545 \mathrm{~nm}$ and a smaller peak at $\sim 650 \mathrm{~nm}$. Tb doping produced bright green EL as compared to Er doping EL. Also the efficiency of energy transfer from nanocrystals to $\mathrm{RE}$ is greater for $\mathrm{Tb}$. When a high electric field is applied to the device, electrons in the 
silicon substrate tunnel into the $\mathrm{SiO}_{2}$ film doped with the RE metals (Fowler-Nordheim tunnelling). Hot electrons transfer energy to the RE ions thereby exciting the RE ions to higher energy levels. RE ions emit light as they decay to their ground states. The light emitted by the RE metal ions leaves the device through the top transparent ITO electrode.

Some studies have also been carried out on other RE elements such as $\mathrm{Gd}$ and $\mathrm{Yb}$ [44]. Strong UV EL has been observed from an $\mathrm{ITO} / \mathrm{SiO}_{2}$ : $\mathrm{Gd} / \mathrm{Si} \mathrm{MOS}$ structure with external quantum efficiency above $1 \%$ [45]. Strong Blue violet EL at $390 \mathrm{~nm}$ has also been reported with Ge 3+ implanted structures [46].EL has been observed with $\mathrm{Yb}$ at $980 \mathrm{~nm}$ with external quantum efficiency of $0.1 \%$ [44].

\subsection{Silicon on Insulator Wafers (SOI)}

SOI wafers are widely used in CMOS applications and continuous research is underway to find SOI applications in photonics [32]. SOI wafer offers many advantages over silicon wafer. In SOI wafers a uniform layer of silica is sandwiched between a thick silicon substrate and a thin surface layer of crystalline silicon. The thickness of crystalline silicon and buried silicon dioxide layer depends on the fabrication process but thicknesses ranging from a few tenths of a micron to several microns are common [33]. The different ways of manufacturing SOI substrates are explained in brief in the next section.

\subsubsection{SIMOX (Separation by Implanted Oxygen)}

SIMOX uses a high energy (200 keV) oxygen implant at extremely high dose $\left(10^{18} \mathrm{~cm}^{-2}\right)$ to form the buried oxide. The technique requires that the substrate be held at a temperature of approximately $600{ }^{\circ} \mathrm{C}$ throughout the implant to maintain the crystallinity 
of the surface layer via solid phase epitaxy. After implantation the buried oxide is nonstoichiometric. Wafers are annealed close to the melting point (typically near $1350{ }^{\circ} \mathrm{C}$ ) to segregate oxide and silicon. At the end of anneal the buried oxide is stoichiometric $\mathrm{SiO}_{2}$ and the defect density in the Si film is low enough to support device fabrication. [34].

\subsubsection{BESOI (Bond and Etch-back SOI)}

In this method two oxidized silicon wafers are electrostatically bonded. One wafer is then etched back using either chemical-mechanical polishing or plasma etching to leave a thin silicon film. This technique has the advantage that almost any buried oxide and silicon film thicknesses are possible, but has the disadvantage that two bulk wafers must be consumed to produce one SOI substrate.

\subsubsection{Smart Cut}

In this process a silicon wafer is oxidised and then massively implanted through the oxide layer with protons (hydrogen nucleus). Another silicon wafer is bonded to the oxide layer and this wafer acts as a substrate for the SOI wafer. A stress fracture is formed along the plane of hydrogen implant during the annealing and is called smart cut. A thin layer of silicon is left behind on the top of buried oxide when the original silicon wafer is removed from the trilayer stack. Finally the SOI wafer is annealed and polished. 


\subsection{Thin Film Reflectors}

A phase shift of $180^{\circ}$ takes place when a light wave is reflected from a medium with lower refractive index than the adjoining medium whereas the phase shift becomes zero if the medium has higher refractive index than the one adjoining it. Depending upon the phase shift, incident and reflected light waves interfere either constructively or destructively. Reflection at the top and bottom of thin films causes the light wave to split into two components. If the relative phase shift is $180^{\circ}$, the resultant of the two components is the difference of their amplitudes and waves are said to interfere destructively, if the relative phase shift is zero or a multiple of $360^{\circ}$ then the resultant of the two components is the sum of their amplitudes and waves are said to interfere constructively.

A stack of alternate high and low index films form a basic thin-film structure with each layer one quarter wavelength in thickness[35]. Low index layers provide a phase shift of $180^{\circ}$ to the reflected waves whereas high index layers do not cause any phase shift to the reflected waves. All the components of the incident light reflected from the various boundaries of the thin-film structure interfere constructively at the front surface. The effective reflectance of the thin film structure can be optimised with the number of layer used in the structure. High reflectance can be obtained using a large number of thin films. In such kind of thin- film structures, high reflectance is obtained over a limited range of wavelengths and a big change in reflectance is observed outside this range [36].

High reflectance can be obtained from a stack of quarter-wave dielectric layers of 
alternate high and low index. This is due to the constructive interference of waves at the front surface of the assembly. 


\section{Chapter 3 Theory and Modeling}

In this chapter the effectiveness of the SOI back reflector for RE doped oxide light emitting devices is examined theoretically. The reflection coefficient of the SOI structure is first evaluated at a fixed wavelength assuming no absorption in the Si film. SOI structures with $\mathrm{Si}$ and buried oxide film thicknesses exactly matched to the RE emission peak are considered, as are structures that can be realized using SOI material available at Carleton University. The effect of loss in the $\mathrm{Si}$ is then added to the analysis using the best available experimental data. Finally the total increase in light emission with a SOI back reflector is estimated by integrating over wavelength, both for ideal $\mathrm{Si}$ and $\mathrm{SiO}_{2}$ layer thicknesses, and for the thicknesses that could be obtained with wafers available at Carleton University.

\subsection{Reflection Coefficient}

Modelling of the electroluminescent devices fabricated in this project is based on the simple and well established formula of reflection. The three layers of the SOI substrate act as a multiple dielectric interface. In case of multiple dielectric interface, the electric field reflection coefficient $R$ depends on the thickness of the different layers used in the interface. In order to get maximum reflection, the thickness of these layers needs to be optimised. The reflection coefficient formula for two layer dielectric interface with light 
at normal incidence is given below [37]. Light emission in the ELD's is isotropic in nature but to make calculations simpler only normal incidence of light is considered.

$$
R=\frac{n_{1}-n_{234}}{n_{1}+n_{234}}
$$

where $n_{234}=n_{2} \frac{n_{34}+j n_{2} \tan \left(\beta_{2} d_{2}\right)}{n_{2}+j n_{34} \tan \left(\beta_{2} d_{2}\right)}$

$$
\text { and } \quad n_{34}=n_{3} \frac{n_{4}+j n_{3} \tan \left(\beta_{3} d_{3}\right)}{n_{3}+j n_{4} \tan \left(\beta_{3} d_{3}\right)}
$$

$$
\text { With } \quad \beta=\frac{2 \pi}{\lambda}
$$

The power reflection coefficient is equal to $|R|^{2}$.

Fig. 3.1 illustrates the optical structure modelled here. Light is emitted in a Tb-doped deposited oxide film which is assumed to have the refractive index of pure $\mathrm{SiO}_{2}$. Light emitted downwards encounters a thin Si film of index $n_{2}$ and thickness $d_{2}$ formed over a buried oxide of thickness $d_{3}$ and index $n_{3}$ on a silicon substrate of index $n_{4}$. 


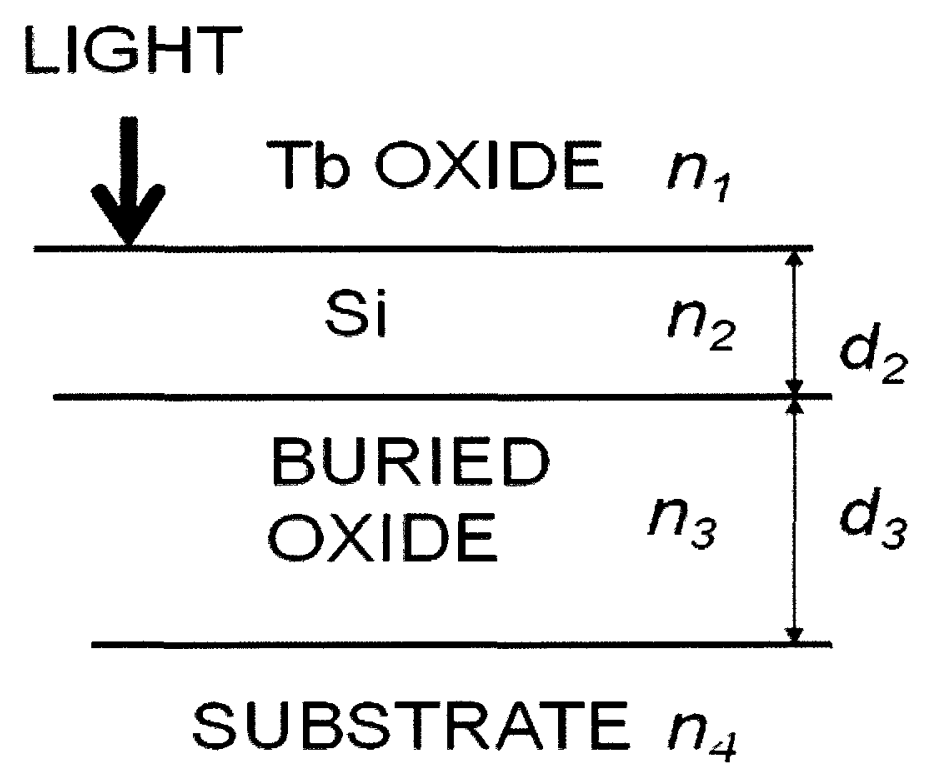

Figure 3.1 Structure for optical modeling of electroluminescent devices

\subsection{Reflectance Calculations for Different Values of $d_{2}$ and $d_{3}$}

SOI wafer has three layers i.e. Silicon - Silicon dioxide - Silicon which make an interface having different refractive indices. Silicon dioxide is buried between the two silicon layers which results in the formation of interface with HLH indices. From equations 3.1 to 3.4 for a given wavelength $\lambda$ (for example for the wavelength of peak $\mathrm{Tb}$ emission, $545 \mathrm{~nm}$ ) maximum reflection will take place if $d_{2}$ and $d_{3}$ are $\lambda / 4$. In order to calculate the reflectance at different values of $d_{2}$ and $d_{3}$ a Matlab program was used. Values for the complex refractive indices of $\mathrm{Si}$ and $\mathrm{SiO}_{2}$ as a function of wavelength were taken from Ref. [38]. Values at the Tb peak emission wavelength of $545 \mathrm{~nm}$ are listed in Table 3.1. 
Table 3.1 Refractive indices $\mathrm{n}$ for $\mathrm{Si}$ and $\mathrm{SiO}_{2}$ at $\lambda=545 \mathrm{~nm}$ (Tb emission peak) [38].

\begin{tabular}{cc}
\hline Material: & $\mathbf{n :}$ \\
\hline \hline $\mathrm{Si}$ & $4.10175+\mathrm{j} 0.044$ \\
$\mathrm{SiO}_{2}$ & 1.46 \\
\hline
\end{tabular}

The emission spectrum for Tb-doped $\mathrm{SiO}_{2}$ is shown in Fig. 3.2. The Matlab program was modified to numerically integrate the emission-reflectance product over this spectrum. Assuming that half the light is emitted towards the substrate, and that there is perfect transmission of light through the top conductive electrode, the use of the SOI substrate allows $90 \%$ of the light emitted by the $\mathrm{Tb}$ to escape the device, compared to $61 \%$ emission for the bulk control. 


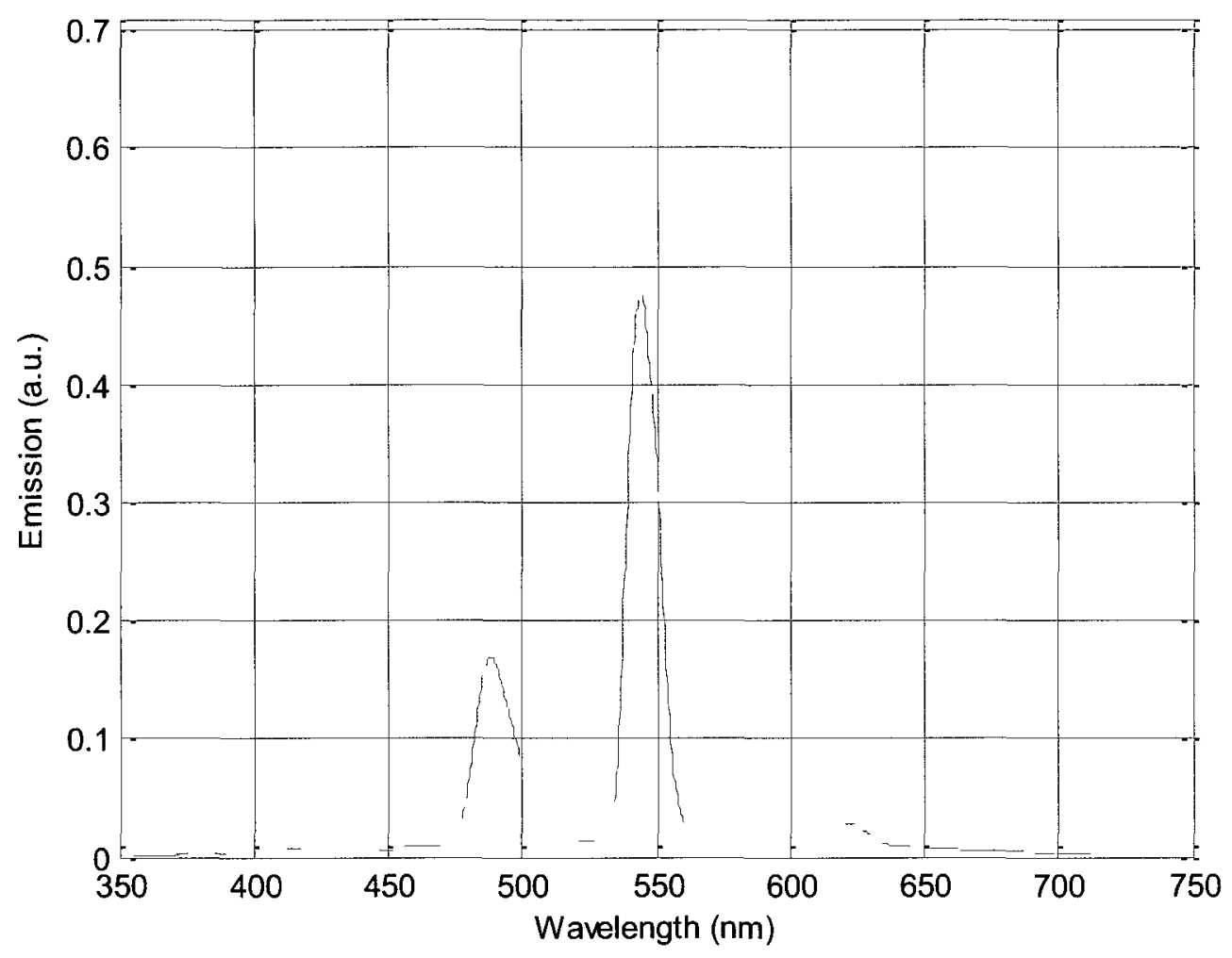

Figure 3.2 Normalized emission spectrum for Tb-doped $\mathrm{SiO}_{2}[39]$.

\subsection{Optical Absorption in Si Film}

Relatively heavy doping of the Si film is required to provide a low-resistance lateral path for current from the Si film contact into the region under the emitting oxide. Heavy doping is also required to ensure that the Si film does not deplete. Doping levels up to $10^{20} \mathrm{~cm}^{-3}$ were used here (details are given in ch. 4). There have been few studies of optical absorption in doped Si films. Extrapolating the data of Schmid [40], at this 
doping level the absorption coefficient $\alpha$ at $545 \mathrm{~nm}$ wavelength is only about $10 \%$ higher than in undoped material, where $\alpha \approx 10^{4} \mathrm{~cm}^{-1}$.

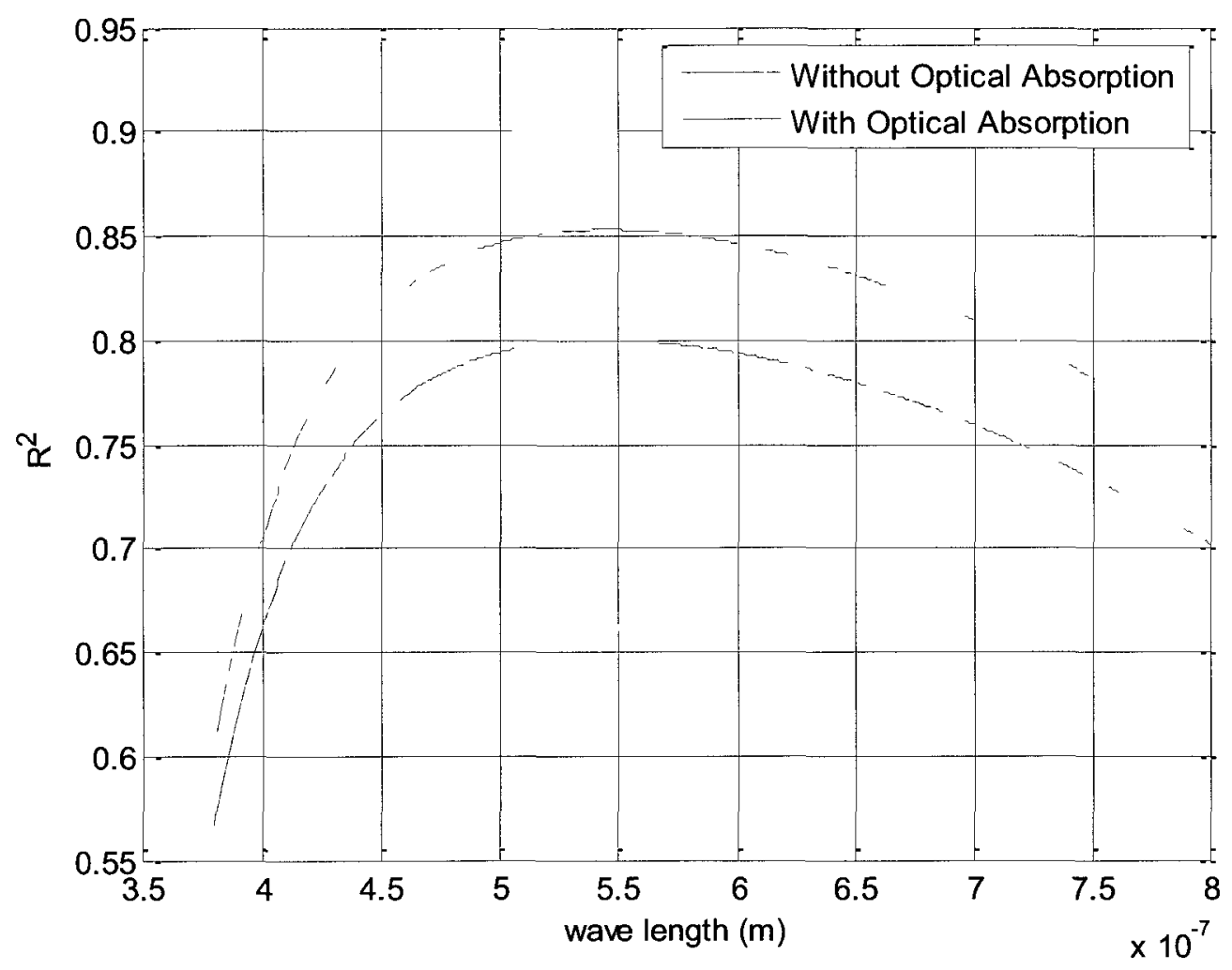

Figure 3.3 Power reflectance versus wavelength for optimum (N/4) Si film and buried oxide thickness.

Figure 3.3 shows the power reflectance with the use of SOI substrate having $\lambda / 4$ thin silicon and silicon dioxide. It also shows the effect of optical absorption in the heavily doped thin silicon layer. 
3.4 Reflection Coefficient Calculations Based On the Wafer Available In Carleton University Fabrication Lab

Two Smart cut SOI wafers from SOITEC were used for this project.

Specifications of the SOI Wafers available in the Carleton Fabrication lab are given in

Table 3.2.

Table 3.2 Parameters of the SOI wafers used in the project

\begin{tabular}{ccc}
\hline Name & Parameter & Value \\
\hline$d_{2}$ & Thickness of medium2 (Thin & $340 \mathrm{~nm}$ \\
& silicon film on SOI wafer) & \\
& Thickness of medium 3 (buried & $1006 \mathrm{~nm}$ \\
$d_{3}$ & oxide in SOI wafer) & \\
\hline
\end{tabular}

Figure 3.4 shows the power reflectance for $d_{2}=\lambda / 4$ and $d_{3}=1006 \mathrm{~nm}$. This buried oxide thickness corresponds approximately to 7.38 quarter wavelengths at the $\mathrm{Tb}$ emission peak. It is observed that plot the shown in Figure 3.4 has more crests and troughs as compared to the plot generated in Figure 3.3 with SOI having $\lambda / 4$ silicon film and buried oxide. This is expected, since with such a thick buried oxide a relatively small change in $\lambda$ can change the optical thickness of the oxide from an odd to an even number of quarter wavelengths, shifting from constructive to destructive interference. 


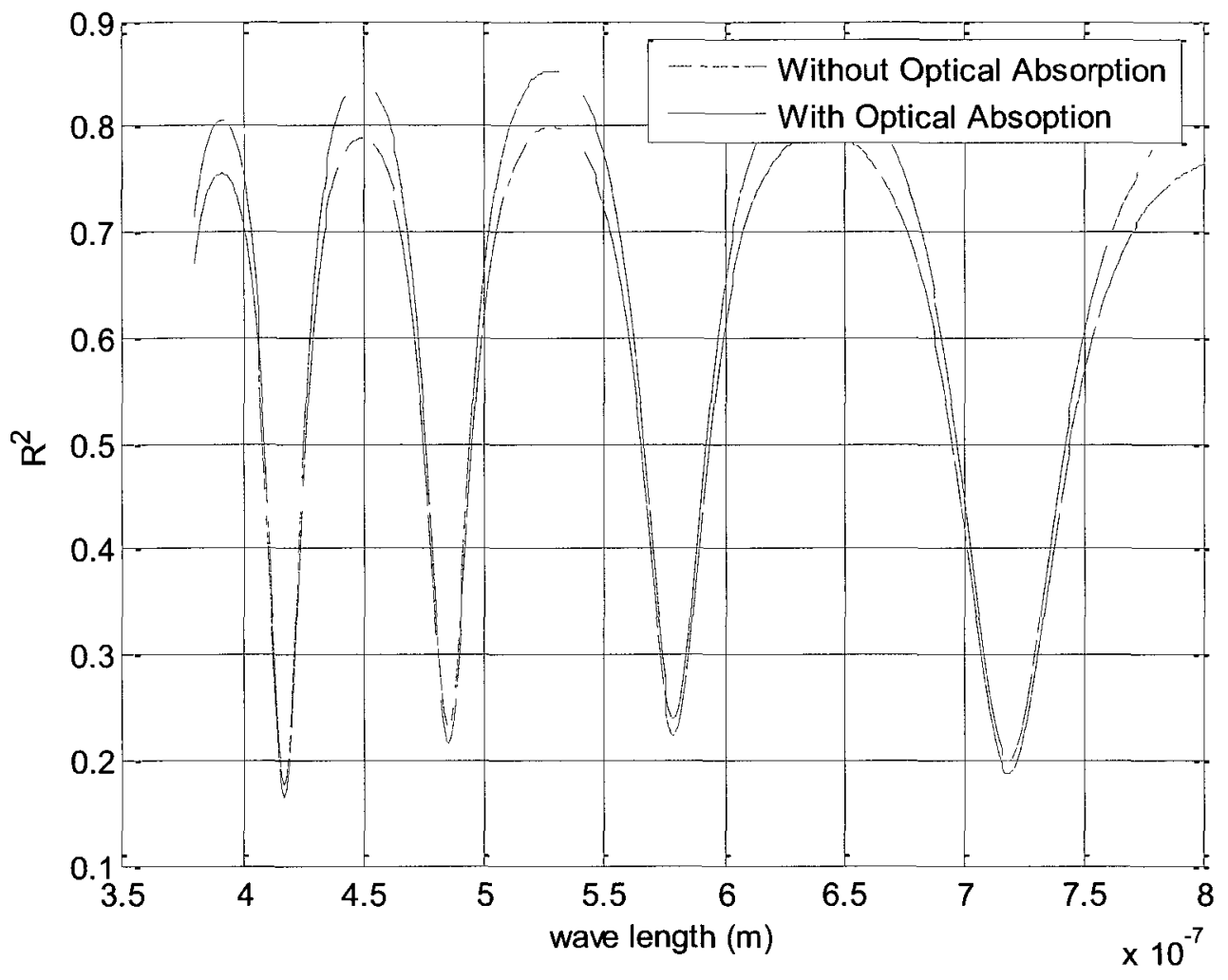

Figure 3.4 Power reflectance versus wavelength for $(\lambda / 4)$ Si film and $1006 \mathrm{~nm}$ buried oxide thickness.

\subsection{Comparison of Light Output Using SOI Wafer and Bulk Substrate.}

For the SOI substrates available for this project, the buried oxide thickness closest to an odd integer multiple of $\lambda / 4$ at the $\mathrm{Tb}$ emission peak was $1006 \mathrm{~nm}$. Use of such a thick buried oxide makes the back reflector less effective for wavelengths far from the $\mathrm{Tb}$ emission peak. Figure.3.5 compares the output spectrum expected for a $\lambda / 4 \mathrm{Si}$ film thickness over $1006 \mathrm{~nm}$ buried oxide to that of a bulk substrate device. Even with this non-optimum buried oxide thickness, the model predicts the SOI back reflector should improve light output by $\approx 35 \%$ integrated over the $\mathrm{Tb}$ emission spectrum. 


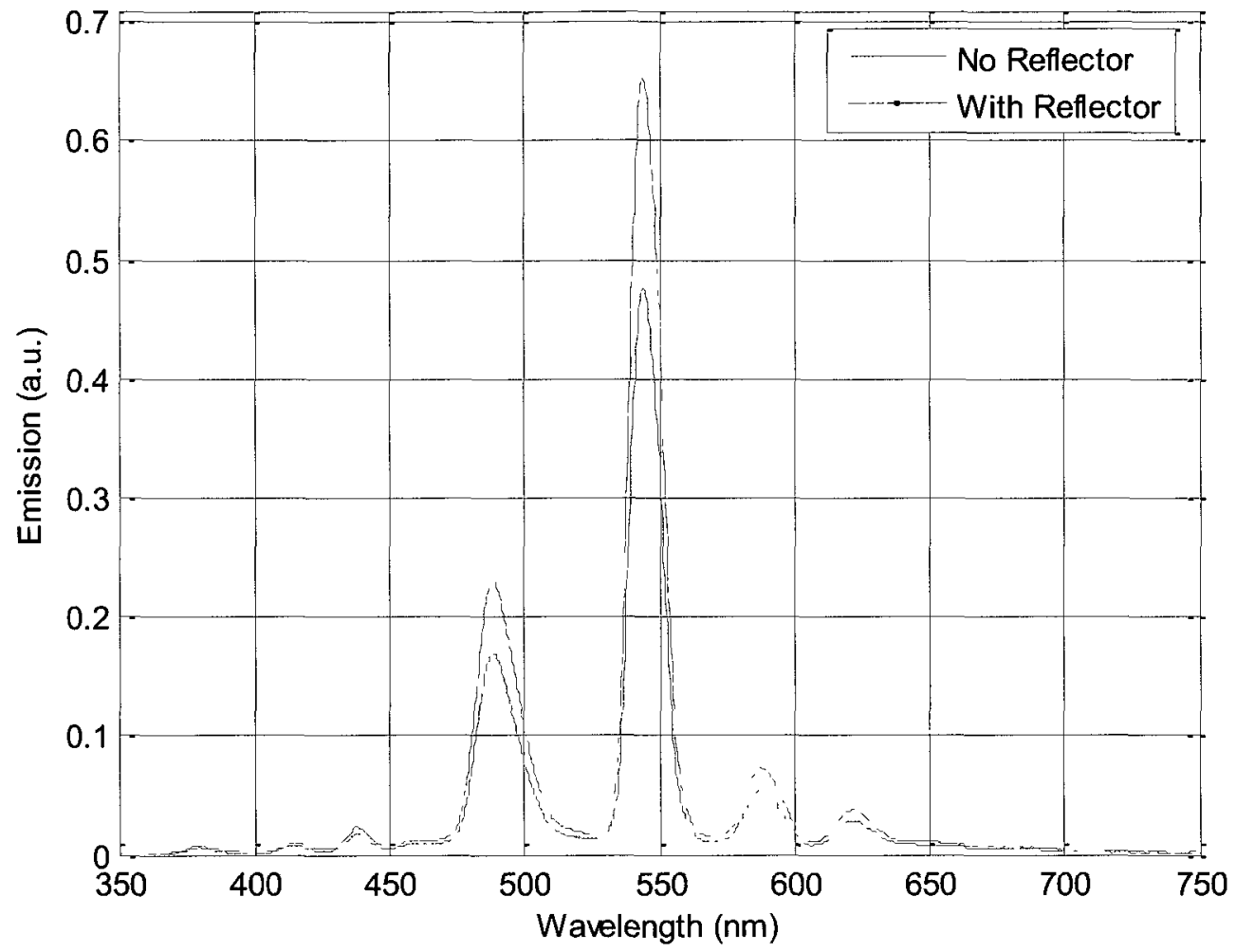

Figure 3.5 Predicted output spectrum for $\lambda / 4$ Si film thickness over $1006 \mathrm{~nm}$ buried oxide. 


\section{Chapter 4 Device Fabrication}

In this chapter a detailed explanation of the steps involved in the fabrication of SOI-based ELDs is given. The specifications of the SOI starting material are also covered in this chapter.

\subsection{Device Structure}

The cross-section through a typical device of the type reported here is shown in Fig. 4.1 Unlike earlier electroluminescent $\mathrm{SiO}_{2}$ devices [39], the devices fabricated here must be contacted from the front surface, not through the bulk. This requires that current flow laterally through the thin silicon film into the device. To obtain maximum light emission the Si film in the emitting region must be an odd integer multiple of $\lambda / 4$ thick, where $\lambda$ is the wavelength of peak emission. If the film is too thin, resistive voltage drops will block emission from the center region of the device. Conversely, as the film thickness is increased more light is absorbed in the silicon. For the Tb emission peak at $545 \mathrm{~nm}$, a $\lambda / 4$ film thickness corresponds to a physical thickness of just $32 \mathrm{~nm}$. Current densities of approximately $100 \mathrm{mAcm}^{-2}$ at bias voltages of near $30 \mathrm{~V}$ are expected in operating devices [39]. An upper bound on the resistive voltage drop across the Si thin film can be obtained by assuming that all the current required by the device must flow from one edge to the other. For a typical device with square layout geometry, this corresponds to the 
current flowing through one square of Si film resistor. The largest voltage drop will be found for the largest device area- in this case $1 \mathrm{~mm}^{2}$, giving a current of $1 \mathrm{~mA}$. The $\mathrm{Si}$ film doping used here is estimated to be between $10^{18}$ and $10^{19} \mathrm{~cm}^{-3}$. In the latter case the electron mobility is approximately $100 \mathrm{~cm}^{2} \mathrm{~V}^{-1} \mathrm{~s}^{-1}$ [41], giving a sheet resistance $R_{S}$ of about $2 \mathrm{k} \Omega / \square$. The larger value of $R_{S}$ gives a resistive voltage drop of just $2 \mathrm{~V}$, which should be negligible compared to the $30 \mathrm{~V}$ supply. For this reason relatively thin Si films were used here. The Si film was first uniformly thinned to $3 \lambda / 4$, and then the Local Oxidation of Silicon (LOCOS) technique was used to selectively thin the active areas of some devices to $\lambda / 4$, as shown in Fig. 4.1. This was done to provide information on how strongly the Si film attenuates light.

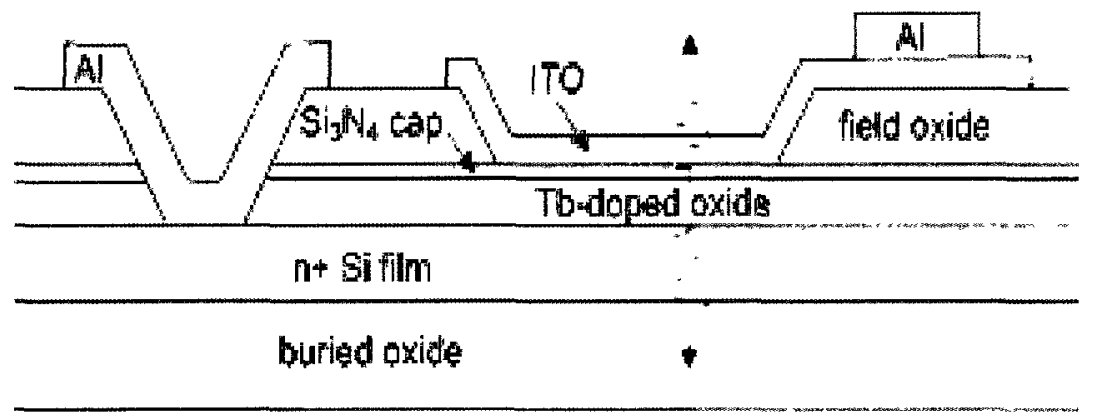

Si substrate

Figure 4.1: Tb-doped oxide electroluminescent device structure on SOI.

\subsection{Device Layout}

A mask set for the formation of SOI electroluminescent devices was prepared using the L-Edit mask design software. The overall layout is shown in Fig. 4.2. The chip contains test devices with sizes ranging from $250 \mu \mathrm{m}^{2}$ to $1 \mathrm{~mm}^{2}$. There are also rectangular devices with length much greater than width to examine the effect of Si film sheet 


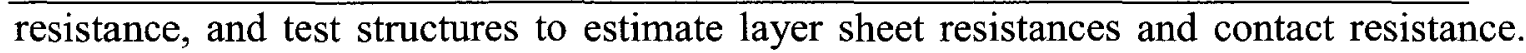
All device sizes have examples with $\lambda / 4$ and $3 \lambda / 4$ film thicknesses. Fig. 4.3 shows a close-up view of the layout for a typical $250 \mu \mathrm{m}$ square device. Contact to the Si thin film and ITO top electrode surrounds the active area.

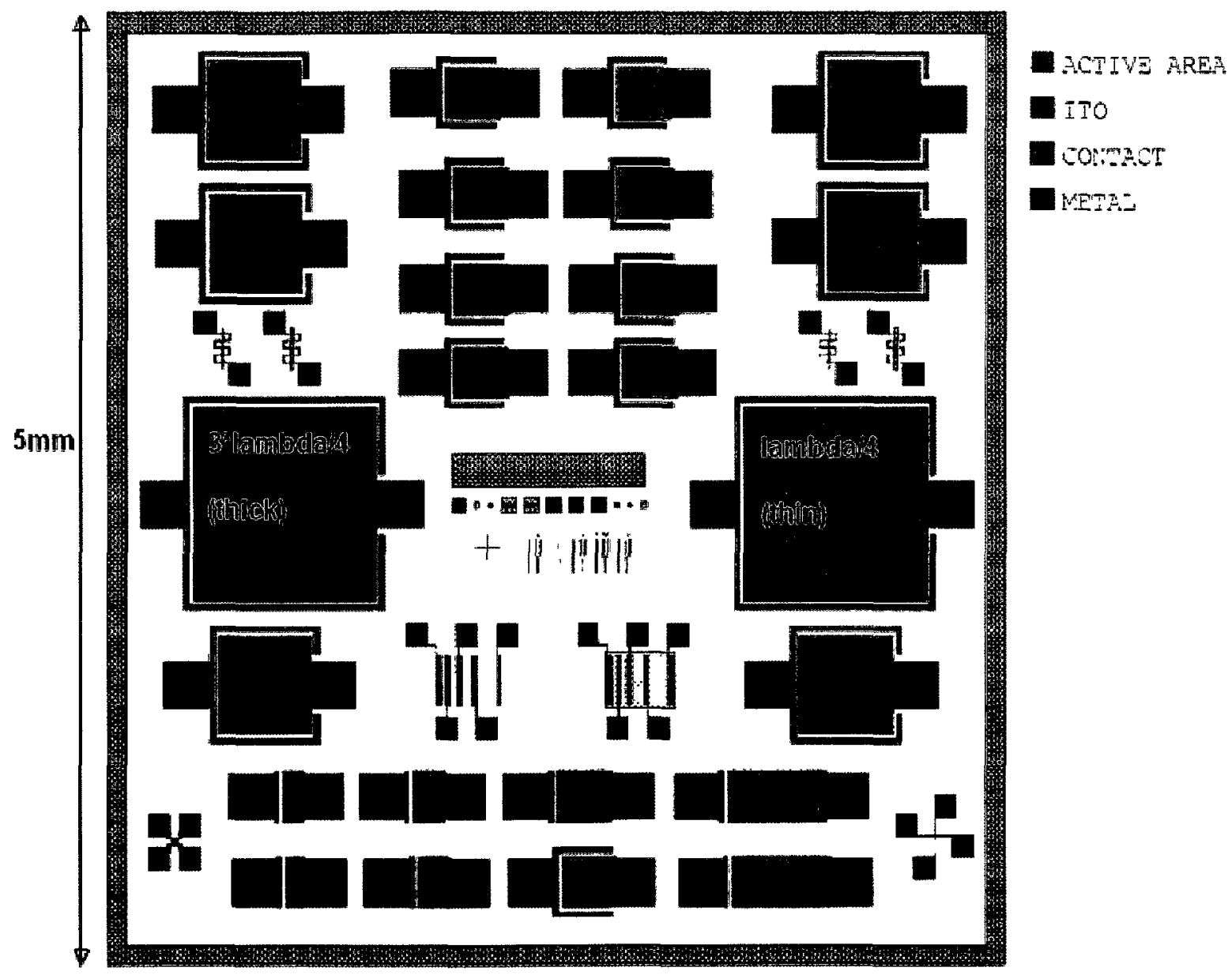

Figure 4.2: Overall layout of the SOI Electroluminescent devices. 


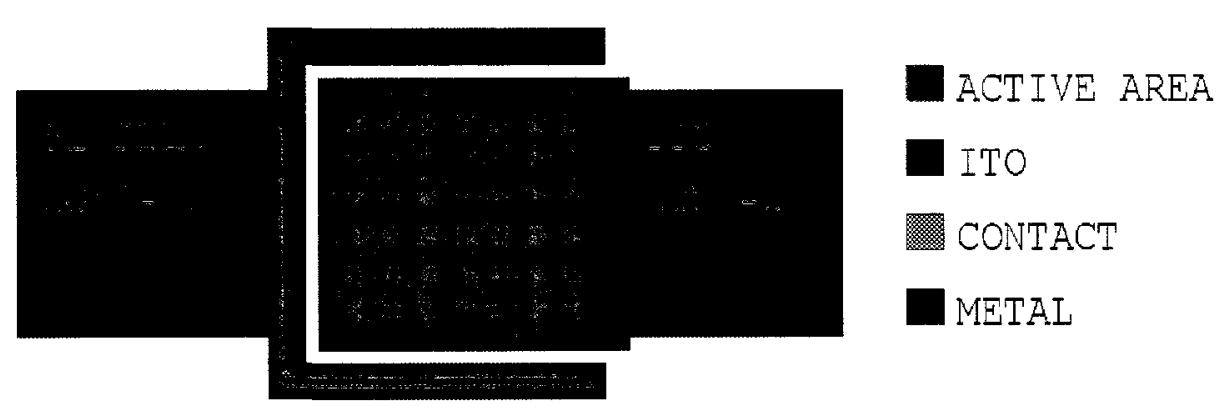

Figure 4.3 Layout for a typical $250 \mu \mathrm{m}$ square device

\subsection{Substrate Preparation}

Two $100 \mathrm{~mm}$ diameter SOI wafers with nominal $10 \Omega \mathrm{cm}$ Si film resistivity from SOITEC Corporation were used as starting material for the experiments reported here. These substrates were manufactured using the Smart cut technique, which produces very uniform silicon film thickness. The buried oxide thickness was $1006 \mathrm{~nm}$ and the initial silicon thickness was $340 \mathrm{~nm}$.

From the results obtained from the calculations done in chapter 3 , the silicon must be thinned down to an odd integer multiple of $\lambda / 4$ to obtain maximum light emission. Here silicon film thickness of $32 \mathrm{~nm}$ and $108 \mathrm{~nm}$ were used. The initial silicon thickness of $340 \mathrm{~nm}$ was reduced to the desired values by oxidation. For better control, and to minimize the oxidation times required, a total of four oxidations were used. After each oxidation, the oxide film was completely removed by etching in hydrofluoric acid to hydrophobia. Details are given in Table 4.1. Oxidations were carried out at $1000{ }^{\circ} \mathrm{C}$. An initial 20 min dry $\mathrm{O}_{2}$ cycle was used to grow a thin oxide to protect the silicon surface, after which the bulk of the oxide was grown in pyrogenic $\mathrm{H}_{2} \mathrm{O}$, since wet oxidation provides a far higher growth rate than dry. Initial estimates for oxidation times required 
were obtained by Suprem 4 simulation [42]. After each oxidation the thickness of oxide grown on a lightly-doped p-type test wafer included in the run was measured to determine the amount of silicon consumed, noting that growth of a thickness $t_{\mathrm{ox}}$ of dry oxide consumes $0.45 \mathrm{t}_{\mathrm{ox}}$ of silicon. The first two oxidations were intended to remove equal amounts of silicon. The time of the second oxidation was adjusted slightly based on the oxide thickness measured after the first oxidation. The short third oxidation was used to introduce a slight variation in the oxide thickness across each wafer. This was done by using a photoresist mask to remove the oxide grown in the second oxidation from only half the wafer. This slows the oxidation rate in those areas already covered by oxide. It is estimated that this procedure resulted in a silicon film thickness difference of $20 \mathrm{~nm}$ across the wafer. The purpose of this deliberate variation was to ensure that at least part of the wafer would come close to the target $\lambda / 4$ or $3 \lambda / 4$ thickness. For the final oxidation, the Local Oxidation of Silicon (LOCOS) technique was used. Standard deviation of 3-4 nm is estimated in the computed Si film thicknesses based on the variation in ellipsometer readings for the monitor wafers. 
Table 4.1 Oxidation Details

\begin{tabular}{|c|c|c|c|}
\hline Time & Desired oxide & $\begin{array}{l}\text { Silicon } \\
\text { consumed }\end{array}$ & $\begin{array}{c}\text { Residual } \\
\text { silicon thickness }\end{array}$ \\
\hline $\begin{array}{l}20 \text { min dry } \\
23 \text { min wet }\end{array}$ & $224 \mathrm{~nm}$ & $98 \mathrm{~nm}$ & $242 \mathrm{~nm}$ \\
\hline $\begin{array}{l}55 \text { min dry } \\
29 \text { min wet }\end{array}$ & $244 \mathrm{~nm}$ & $108 \mathrm{~nm}$ & $134 \mathrm{~nm}$ \\
\hline 10 min dry & $45 \mathrm{~nm}$ & $20 \mathrm{~nm}$ & $114 \mathrm{~nm}$ \\
\hline
\end{tabular}

\subsubsection{Local Oxidation of Silicon}

LOCOS was used to produce split oxide thickness on the same chip. LOCOS [43] begins with a pad oxidation required to reduce the stress caused by the mismatch in the thermal expansion between the silicon nitride and silicon substrate. Here a $50 \mathrm{~nm}$ pad oxide was grown by 11 min of dry oxidation at $1100{ }^{\circ} \mathrm{C}$. The pad oxide is then overlaid with a nitride layer that protects the silicon surface from the oxidizing species. Deposition of nitride layer is done using low pressure chemical vapor deposition (LPCVD) technique which involves the reaction of the following gases:

$$
3 \mathrm{SiH}_{2} \mathrm{Cl}_{2}+4 \mathrm{NH}_{4} \rightarrow \mathrm{Si}_{3} \mathrm{~N}_{4}+6 \mathrm{HCl}+8 \mathrm{H}_{2}
$$

$80 \mathrm{~nm}$ of nitride was deposited using LPCVD technique at $820^{\circ} \mathrm{C}$ for $13 \mathrm{~min}$. 


\subsection{N + Arsenic Implant}

After thinning the silicon on SOI wafer to the required thickness wafers were subjected to heavy arsenic implants to convert the lightly doped p-type Si film to heavily doped $\mathrm{n}+$ type. Wafers were shipped to Kroko Implant Services in Los Angeles, CA for implantation along with some test wafers. Relatively heavy doping of the Si film in the device of Figure 4.1 is required to provide a low-resistance lateral path for current from the Si film contact into the region under the emitting oxide. Heavy doping is also required to ensure that the Si film does not deplete. Wafers were implanted with arsenic using two different doses of $10^{15} \mathrm{~cm}^{-2}$ and $10^{14} \mathrm{~cm}^{-2}$ at $30 \mathrm{keV}$ energy. Two different implant doses were used to examine the effect of film doping on optical absorption. The implant was annealed in $\mathrm{N}_{2}$ at $1000{ }^{\circ} \mathrm{C}$ for 10 min. Suprem4 predicts a final doping concentration in the film of approximately $10^{19} \mathrm{~cm}^{-3}$ for the lighter and $10^{20} \mathrm{~cm}^{-3}$ for the heavier implant. Suprem4 appeared to drastically overestimate the As concentration for thin silicon, predicting values in excess of $-10^{21} \mathrm{~cm}^{-3}$, probably as the result of an overestimate of As segregation from the buried oxide into the Si film.

Figures 4.4 and 4.5 shows the Suprem 4 simulation doping profiles of thick silicon with different doping concentration before annealing. Figure 4.6 and 4.7 shows the Suprem 4 simulation doping profiles of thick silicon with different doping concentration after annealing. The doping profiles for thin silicon were similar to the doping profiles of thick silicon. 
TMA TSUPREM-4 (2008.09S)

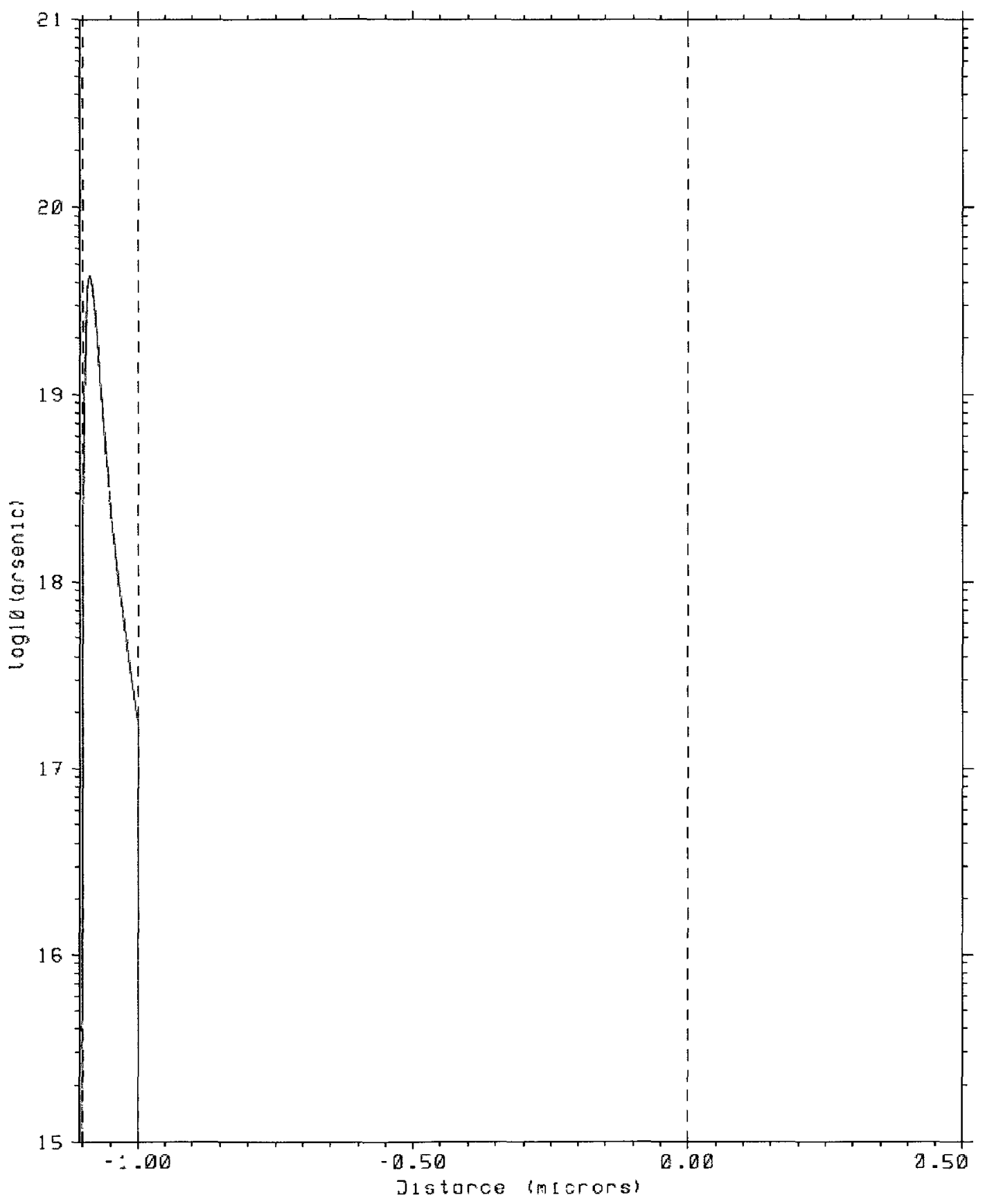

Figure 4.4 Suprem4 simulation of doping profile on thick silicon with low doping before annealing. 


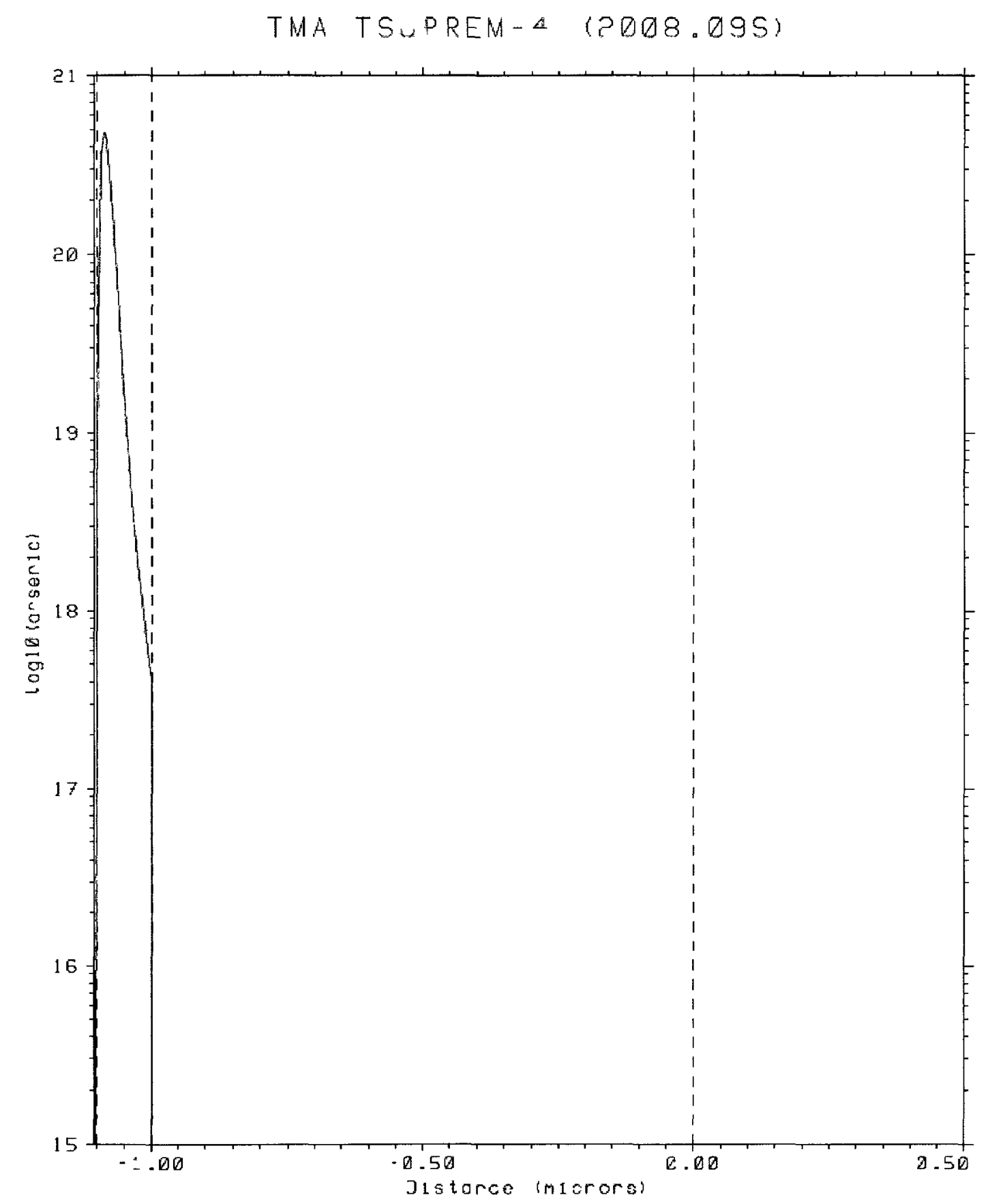

Figure 4.5 Suprem4 simulation of doping profile on thick silicon with high doping before annealing. 
TMA TSLPREM-4 (2DD8.09S)

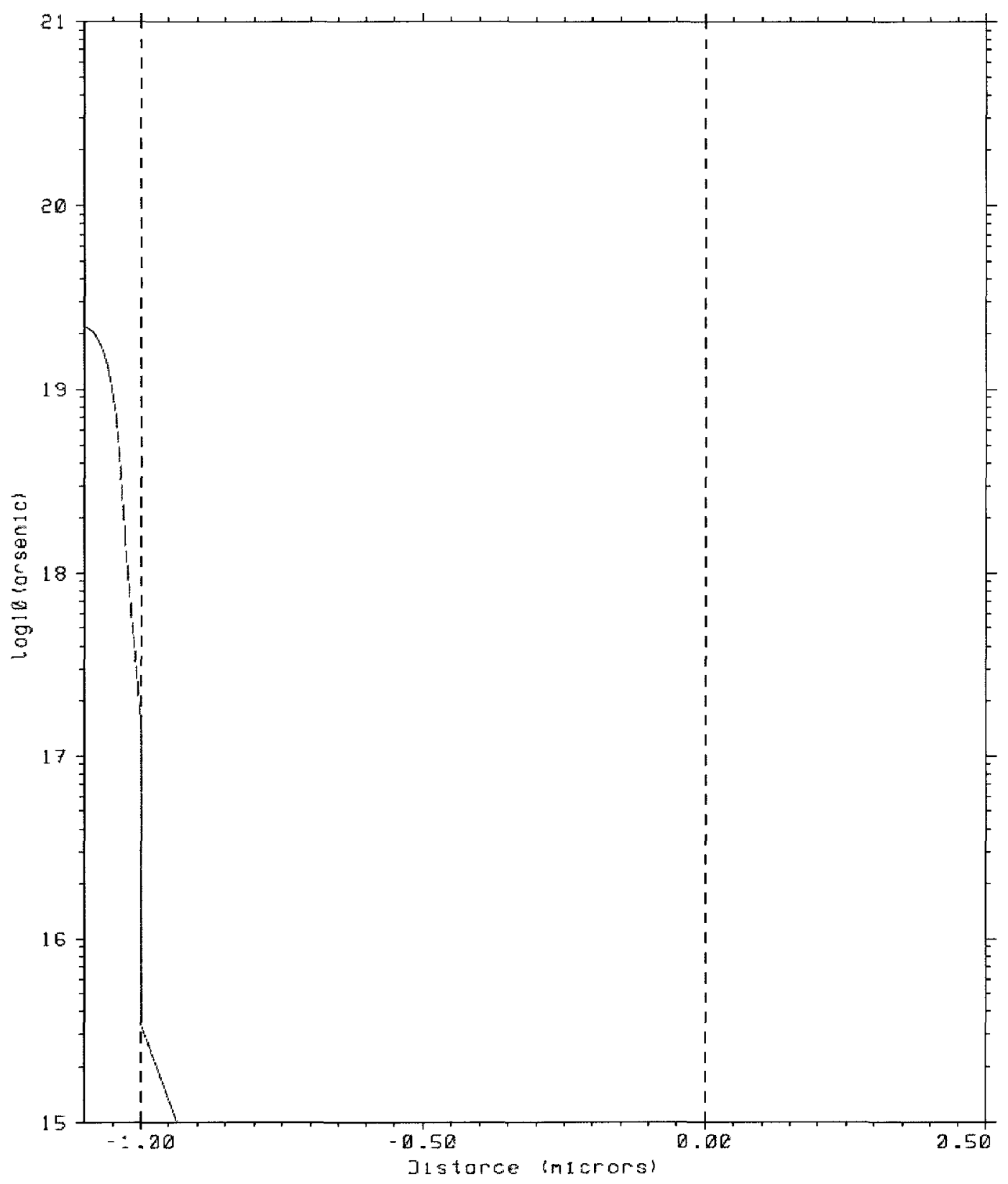

Figure 4.6 Suprem4 simulation of doping profile on thick silicon with low doping after annealing. 


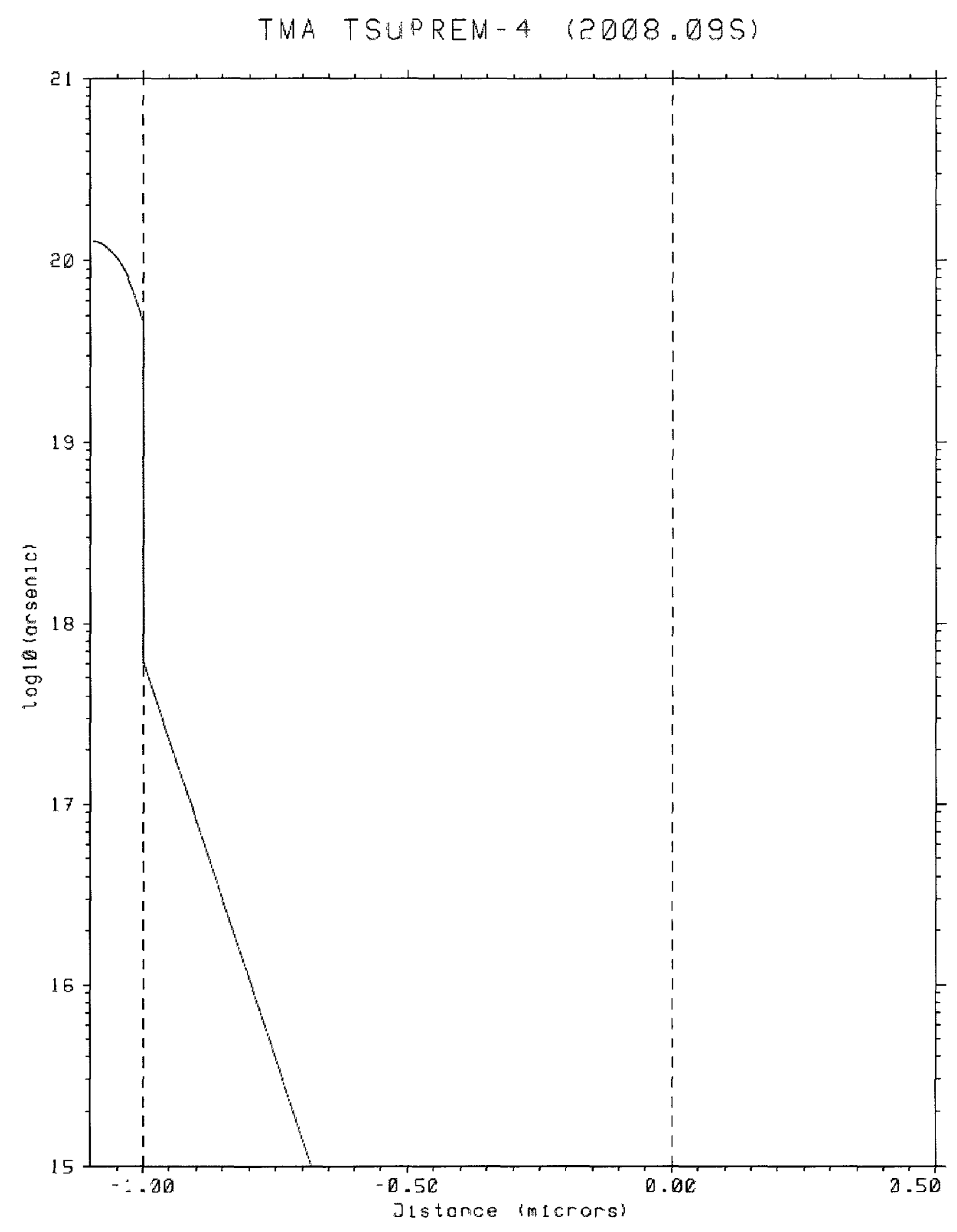

Figure 4.7 Suprem4 simulation of doping profile on thick silicon with high doping after annealing. 


\subsection{Emitter Dielectric Deposition}

Initially the $\mathrm{Tb}$-doped light emitting oxide deposition was to have been carried out at the Canadian Photonic Fabrication Center (CPFC) of the National Research Council using standard processes specified by Group IV Semiconductor. The depositions would have been done on complete $100 \mathrm{~mm}$ diameter wafers to industrial tolerances for repeatability and uniformity. Unfortunately, Group IV Semiconductor ceased technical operations before this deposition could be completed. A direct approach was made to the CPFC to arrange for the deposition, but we were informed that it would be necessary to re-install and re-calibrate the $\mathrm{Tb}$ source at a cost we could not afford. Finally arrangements were made with Prof. P. Mascher's research group to carry out the deposition at the Centre for Emerging Device Technologies at McMaster University in Hamilton, Ontario. The PECVD system used to produce the first light-emitting films in Group IV Semiconductor's initial research was employed. Unfortunately the system only had a 50 mm diameter chuck, so the samples had to be broken into small pieces for the deposition. Six separate deposition runs were required to coat all the samples, and there may have been some variation in film properties from deposition to deposition. The system was not housed in a clean room, which may account for the high density of particulates seen in the completed films. A $10 \mathrm{~nm}$ thick light-emitting oxide film was deposited with nominal 1 atomic percent $\mathrm{Tb}$ doping. A $30 \mathrm{~nm}$ LPCVD nitride layer was next deposited as described above to encapsulate the emitting oxide and serve as an etch stop in the subsequent process step. A $1 \mu \mathrm{m}$ thick LPCVD oxide film was then deposited from 


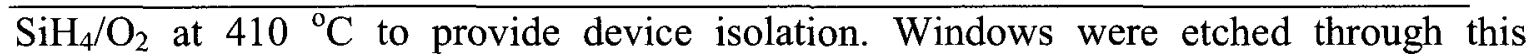
deposited oxide to define active device areas.

\subsection{ITO and Aluminum Deposition}

A $230 \mathrm{~nm}$ thick ITO layer was deposited by reactive sputtering using Semicore SC943 sputtering system and patterned by wet etching in $\mathrm{HCl} / \mathrm{HNO}_{3}$ to form a transparent top electrode. Argon was used in the process with base pressure of $2.4 \times 10^{-7}$ Torr and process pressure of 5 mtorr.

A- $1 \mu \mathrm{m}$ thick Al layer was deposited by e-beam evaporation and patterned by lift-off to provide contact to both the ITO and doped Si film. The lift off process is based on twolayer resist structure. A special lift-off resist LOR10B was used in the project. Another resist S1811 was applied over the lift-off resist LOR10B. The S1811 was exposed and developed. The developer undercuts the LOR10B resulting in a "lip" structure. Here Microposit remover 1165 at $60{ }^{\circ} \mathrm{C}$ was used to dissolve the LOR resist. 


\section{Chapter 5 : Optical Testing and Discussion}

This chapter covers the optical testing of the ELDs fabricated as described in Ch. 4. Detailed information is provided about the test equipment used and the measurementresults.

\subsection{Experiment Setup}

First testing of ELDs was carried out in Carleton University's semiconductor device testing facility. A Wentworth wafer probe station and Agilent HP4155 Semiconductor Parameter Analyzer were used. The voltage applied to the devices was ramped while watching for light emission through the prober microscope. Devices of various sizes were tested, although most measurements were done on $250 \mu \mathrm{m}$ by $250 \mu \mathrm{m}$ square samples. Devices were biased with the ITO as the positive electrode to place the $\mathrm{Si}$ surface in accumulation. Characteristic bright green emission was observed from some devices, although many samples showed catastrophic electrical breakdown before any visible light was emitted. The cause for this variability in device performance is not known, but it is probably associated with the particulate contamination visible in the PECVD oxide. The emission was observed to be completely uniform across all devices for both silicon thicknesses and doping levels, even for high aspect ratio $250 \mu \mathrm{m}$ wide, $500 \mu \mathrm{m}$ long devices contacted from one narrow edge. The uniformity of light emission 
from the samples was judged by human eye. This result indicates that even with the thinnest, most lightly doped $\mathrm{Si}$ layer current crowding is not an issue. A current of $10 \mu \mathrm{A}$ was injected at biases in the range 70 to $100 \mathrm{~V}$. Figure 5.1 shows the typical I-V curve of a test device.

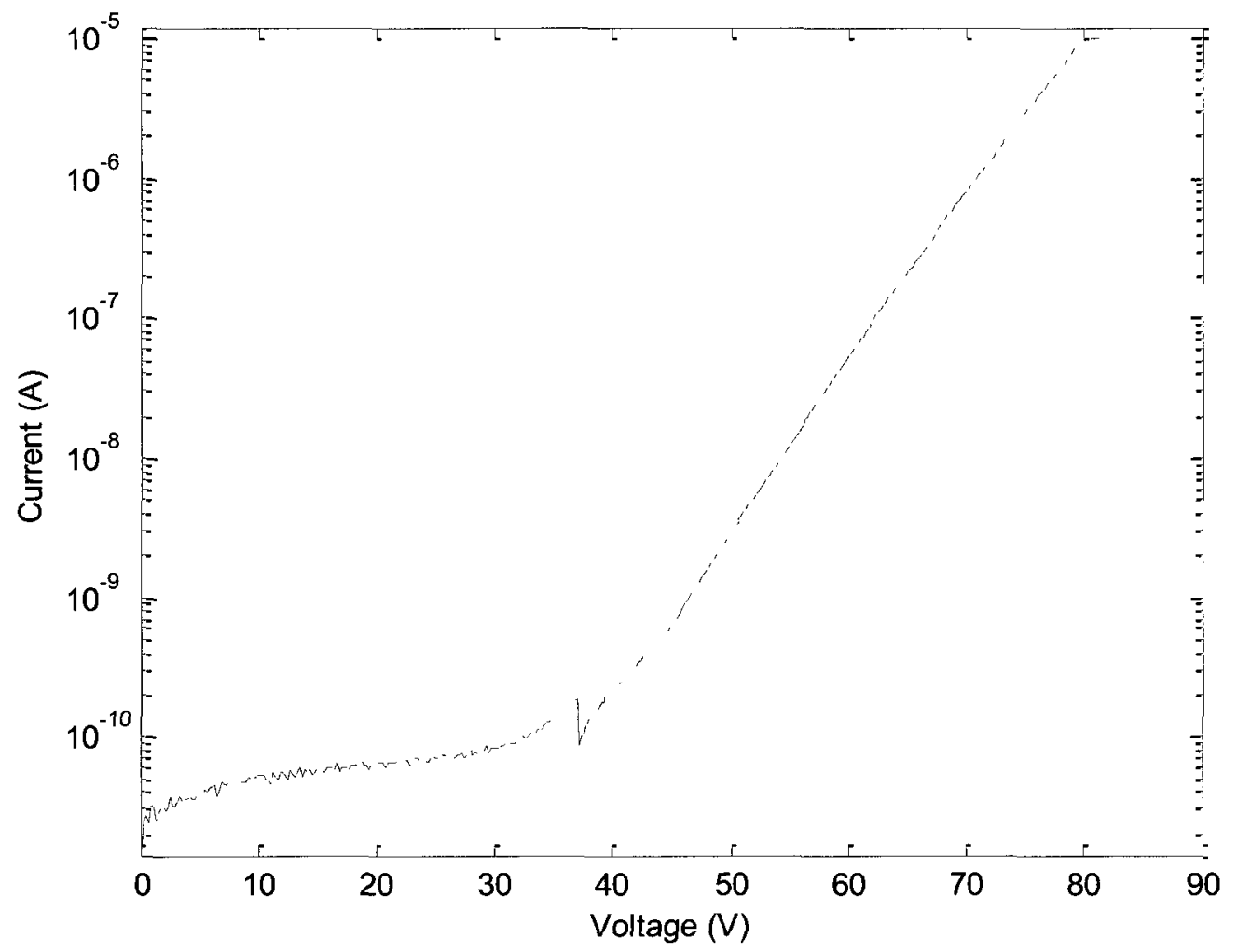

Figure 5.1 Typical I-V curve of test device.

The next step in testing was quantitative measurement of light output from the devices. At this point T.W. MacElwee of Group IV Semiconductor offered access to that company's test facilities, which were already set up to measure ELD light power output. Testing at Group IV was initially carried out using excitation from a Keithley current 
source. A current of $25 \mu \mathrm{A}$ was injected at biases in the range 70 to $100 \mathrm{~V}$.

Unfortunately lifetimes under electrical excitation were found to be very short (typically less than 1 minute) making it difficult to record output spectra. A picture of a failed device with fracture lines visible in ITO is shown in Figure 5.2

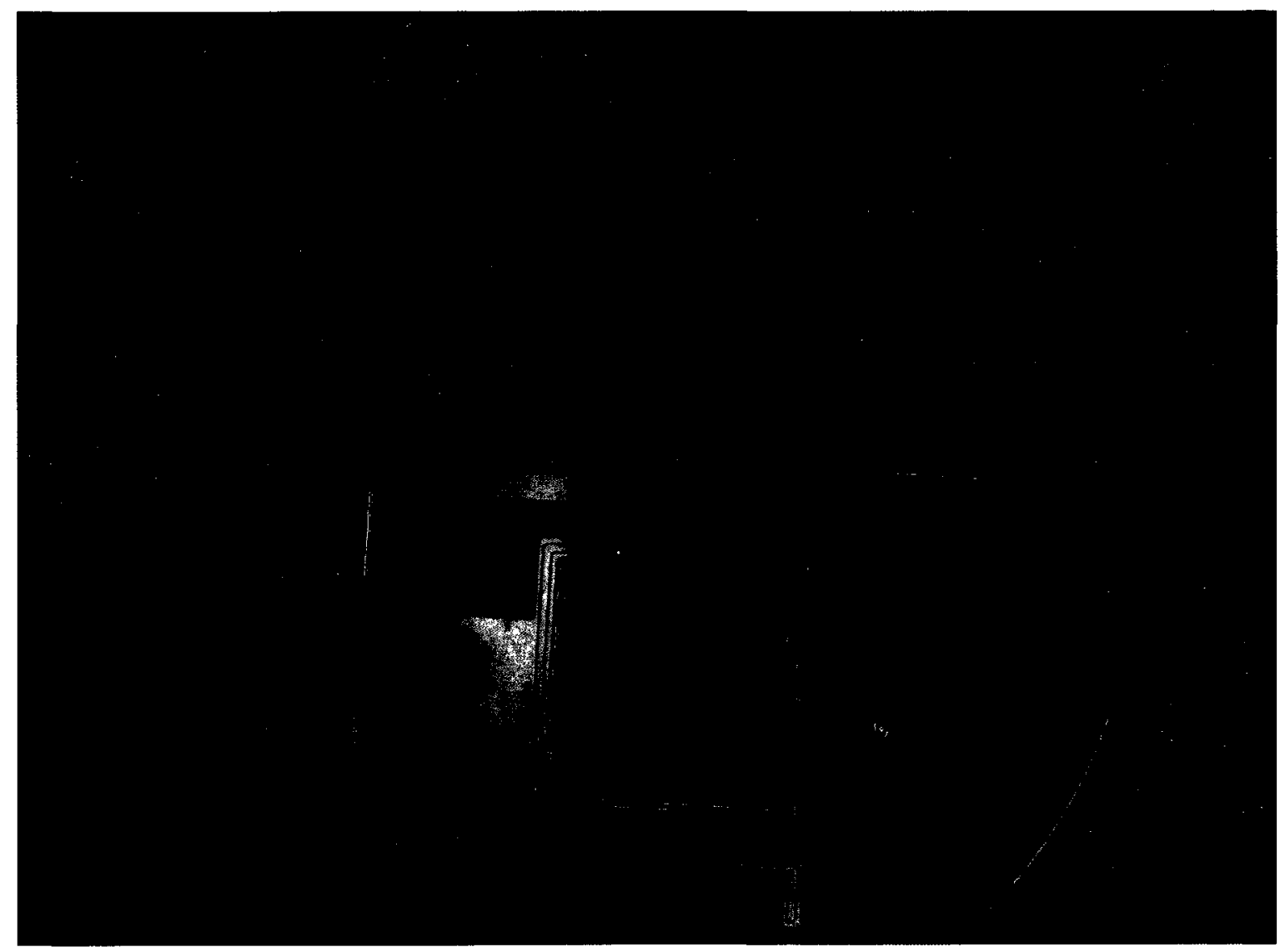

Figure 5.2 Picture of failed device 
Picture shown in Figure 5.3 shows the test equipment used at Group IV Semiconductor.

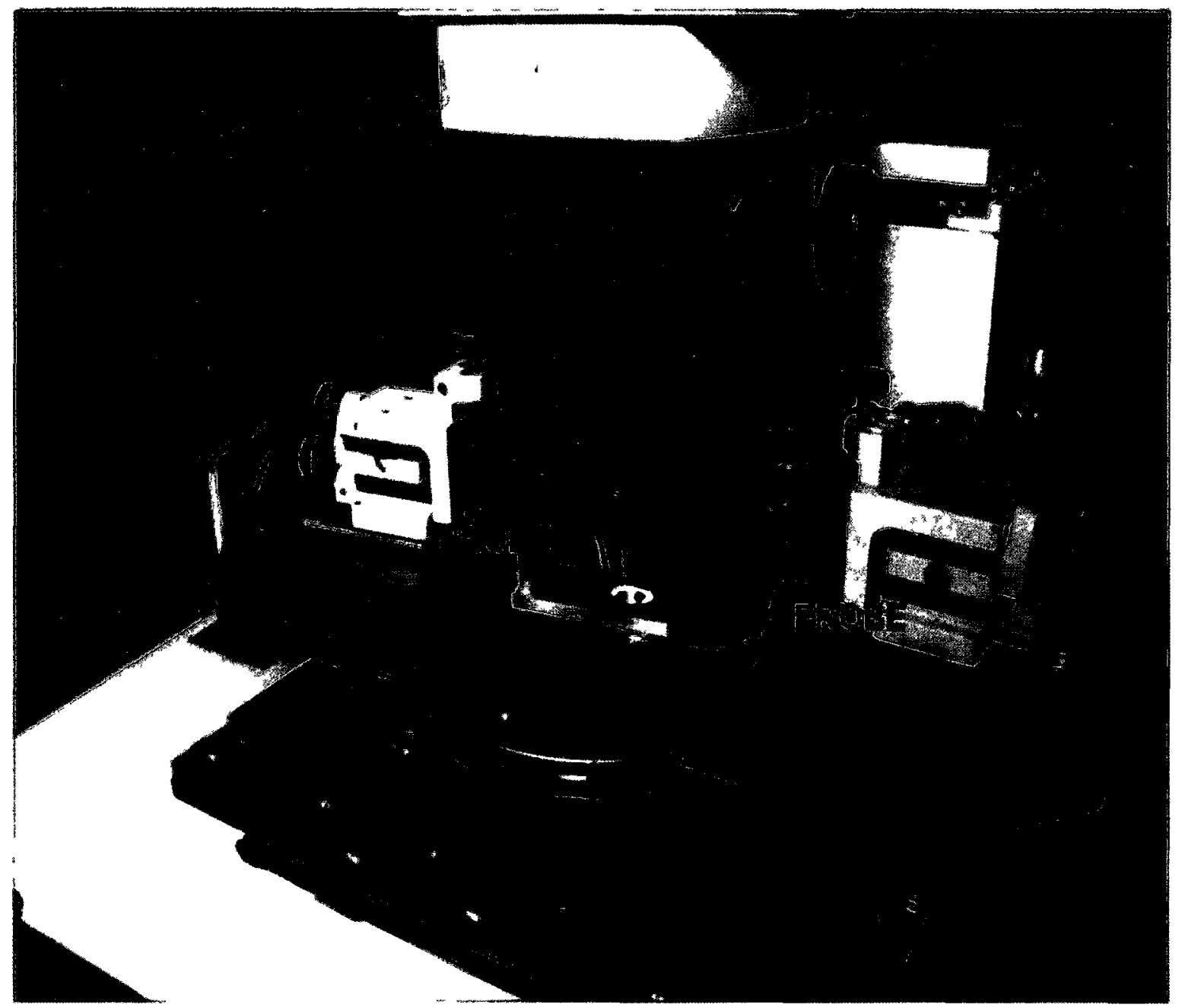

Figure 5.3 shows the test setup at Group IV semiconductor, Kanata.

To obtain spectra, devices were therefore excited with a $325 \mathrm{~nm}$ Kimmon HeCd CW laser providing an output power of approximately $15 \mathrm{~mW}$ at the target. The output spectra obtained with PL for best and worst cases with SOI wafers and also for a bulk substrate control device are shown in Figure 5.4. Although the best SOI device gave higher light output than the control, the variation between samples was too great to 
conclusively demonstrate the advantage of the back reflector. This variation in light output is believed to be the result of non-uniformity and variability in the properties of the Tb-doped PECVD oxide.

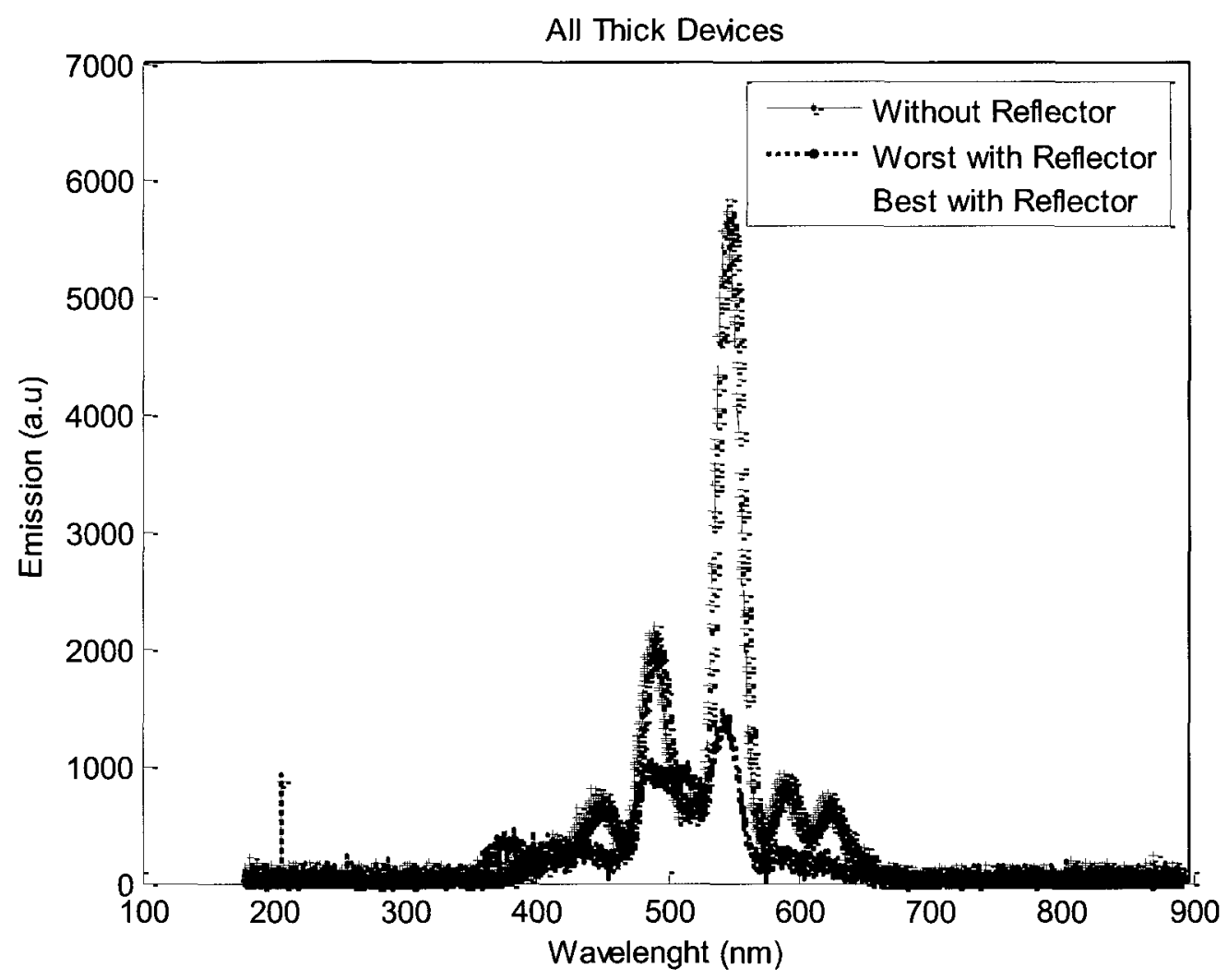

Figure 5.4 Output spectra under photoexcitation (arbitrary units on y-axis)

Figure 5.5 compares typical output spectra for devices with thin $(\lambda / 4)$ and thick $(3 \lambda / 4)$ Si layers on the same chip. The two devices are spaced less than a millimeter apart and have PECVD oxides formed in the same deposition cycle, so the light emission characteristics of the oxides should be very similar. The light output of the thick Si 
device is only about $10 \%$ less than that of the thin device, indicating that light absorption in the $\mathrm{S}_{1}$ film is not having a major impact on the devices, particularly for $\lambda / 4$ films.

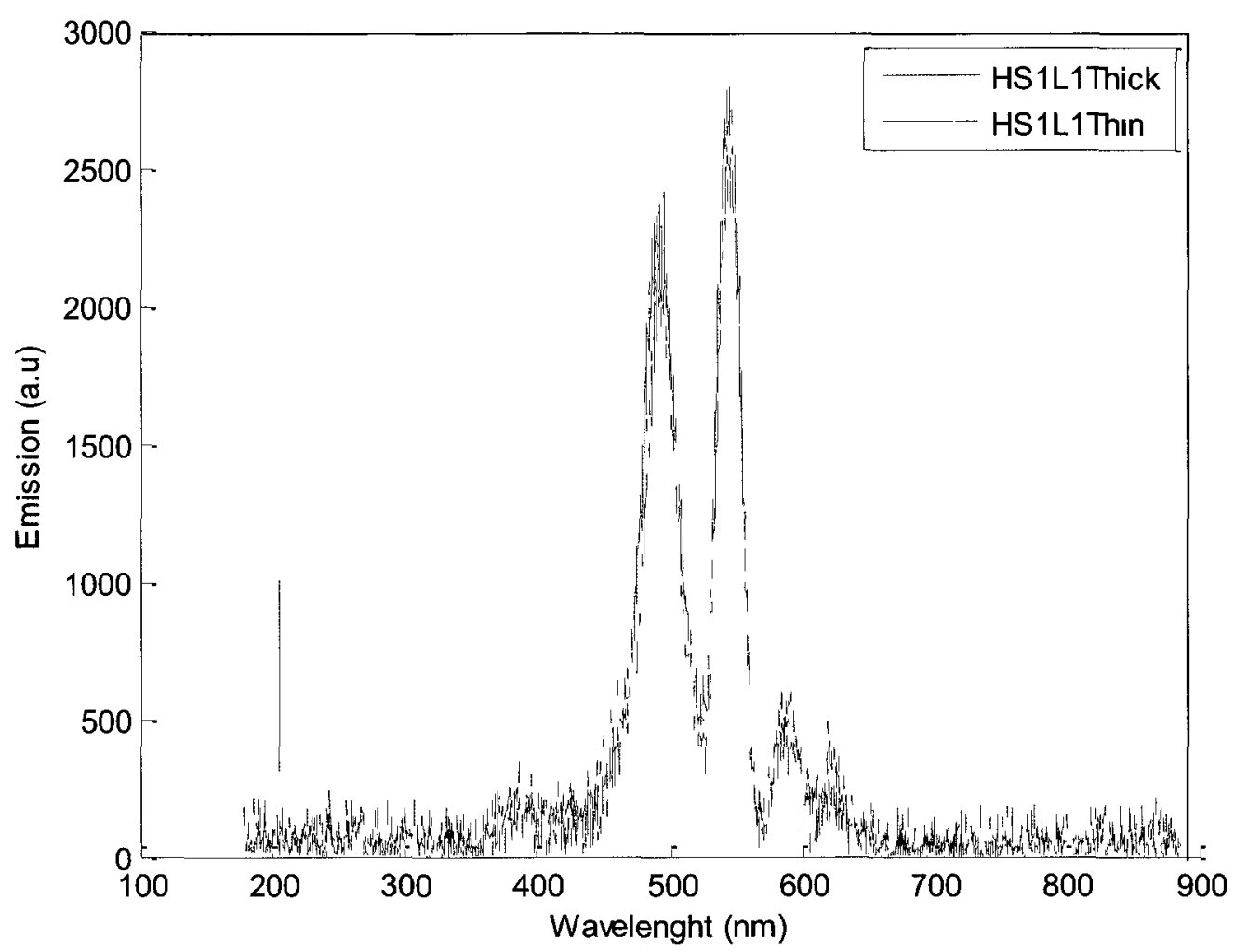

Figure 5.5 Comparison of output spectra for thick and thin Si films on the same chip (arbitrary units on y-axis).

Since sample-to-sample variability precluded direct demonstration of the advantage of the back reflector, using comparisons of the output spectra, our attention was turned to the detailed shape of the spectral peaks to provide some validation of the theory of Section 2. In particular, the relative magnitude of the 495 and $545 \mathrm{~nm}$ peaks in the $\mathrm{Tb}$ spectrum is quite sensitive to changes in thin-film interference effects resulting from changes in the Si film thickness. The model of Section 2 predicts that ratio of peak 
Chapter 5 Optical Testing and Discussion

heights should differ by only $1 \%$ for the 32 and $108 \mathrm{~nm}$ Si film thicknesses used here.

Far larger differences in peak height ratio are predicted for other film thicknesses.

Table 5.1 gives the ratio of the 495 to $545 \mathrm{~nm}$ peak heights for the devices measured here, and indeed the ratio is very similar for the thick and thin devices in every sample.

Table 5.1 Ratio of 545 to $495 \mathrm{~nm}$ peak height for different samples.

\begin{tabular}{cccc}
\hline Sample: & Si Film $(\mathbf{n m}):$ & $\begin{array}{c}\text { Implant Dose } \\
\left(\mathbf{c m}^{-2}\right):\end{array}$ & Peak ratio: \\
\hline HS1L1 & 32 & $1 \mathrm{e} 14$ & 1.16 \\
HS1L1 & 108 & $1 \mathrm{e} 14$ & 1.16 \\
HS1L2 & 32 & $1 \mathrm{e} 14$ & 1.36 \\
HS1L2 & 108 & $1 \mathrm{e} 14$ & 1.21 \\
HS2L1 & 32 & $1 \mathrm{e} 15$ & 1.61 \\
HS2L1 & 108 & $1 \mathrm{e} 15$ & 1.60 \\
HS2L2 & 32 & $1 \mathrm{e} 15$ & 1.31 \\
HS2L2 & 108 & $1 \mathrm{e} 15$ & 1.25 \\
\hline
\end{tabular}




\section{Chapter 6 Results: Conclusion and Discussion}

\subsection{Thesis Summary}

To our knowledge this thesis reports the first rare-earth doped oxide MOS capacitor ELDs with SOI back reflectors. Analysis predicts an SOI back reflector with buried oxide and Si film thicknesses of $\lambda 4$ (where $\lambda$ is the wavelength of the Tb emission peak) should provide a total $35 \%$ increase in light output for a device with a $\mathrm{Tb}$ doped oxide layer. Test devices were fabricated on SOITEC substrates with initial Si thicknesses of $340 \mathrm{~nm}$ and buried oxide thickness of $1006 \mathrm{~nm}$. Selective oxidation was used to thin the Si film to thicknesses of $32 \mathrm{~nm}(\lambda / 4)$ and $108 \mathrm{~nm}(3 \lambda / 4)$. The film was doped in the range $10^{19}$ $10^{20} \mathrm{~cm}^{-3}$ by As implantation. The emitting oxide was deposited by PECVD at McMaster University and contained $1 \% \mathrm{~Tb}$. The emitting oxide was overlaid with a $\mathrm{Si}_{3} \mathrm{~N}_{4}$ cap layer and then with an ITO transparent conductor top electrode. Most testing was done on 250 $\mu \mathrm{m}$ square devices using a $25 \mu \mathrm{A}$ current drive at approximately $75 \mathrm{~V}$. Uniform EL was observed across the device area, indicating that current crowding is not an issue even for the thinnest, most lightly doped Si films. Unfortunately many devices suffered destructive breakdown before EL was observed, and even in those devices which emitted light time to destructive failure was usually less than one minute. For these reasons light output was measured using PL rather than EL, with devices excited using a $\mathrm{HeCd}$ laser. 
Chapter 6 Results: Conclusion and Discussion

Comparison of the output spectra for thick and thin Si films demonstrated that light absorption in the Si film has a relatively minor effect on the emission efficiency, particularly for a $\lambda / 4$ film.

\subsection{Recommendations for Future Work}

This thesis has provided a first demonstration of the use of back reflectors with Tb-doped oxide ELDs. The limited number of samples which could be processed and variation in the properties of the deposited oxide from sample to sample precluded a direct demonstration of enhanced light emission from devices with back reflectors. Fabrication of more samples with a better controlled doped oxide deposition system to verify the advantage of the back reflector would be highly desirable.

The SOI structure lends itself to the integration of control electronics with ELD emitters to produce a light emitting array. Experimental demonstration of such an array would be a very interesting project. 


\section{Appendix A - Fabrication Run Sheet}

Starting material: Two 4" SOITEC wafers $1 \mu \mathrm{m}$ buried oxide $340 \mathrm{~nm}$ Si, label HS-1, HS-2

1. FIRST SI THINNING OXIDATION (blanket) $1000^{\circ} \mathrm{C} 20$ min dry, 23 min wet target oxide thickness: $224 \mathrm{~nm}$ target Si removal: $98 \mathrm{~nm}$ include $2-4$ " $P$ type test wafers

a) RCA clean

b) Oxidation tube temperature $1000^{\circ} \mathrm{C}$

5 min preheat

2 " every 6 sec push

20 min oxidation

23 min oxidation

5 min anneal

$2 "$ every $15 \mathrm{sec}$ pull

$10 \mathrm{~min}$ cool
$\mathrm{O}_{2}$

$\mathrm{O}_{2}$

dry $\mathrm{O}_{2}$

$\mathrm{O}_{2}+$ pyrogenic $\mathrm{H}_{2} \mathrm{O}$

$\mathrm{N}_{2}$

$\mathrm{N}_{2}$

$\mathrm{N}_{2}$

Target thickness: $224 \mathrm{~nm}$

Thickness measured on test wafer $204.1 \mathrm{~nm}$ 


\section{OXIDE THICKNESS ASSESSMENT ON TEST WAFER, OXIDE ETCHBACK} confirm time for second oxidation

a) remove oxide

etch in $10 \% \mathrm{HF}$ until oxide removed

estimated etch time:5 $\mathrm{min}$

actual etch times : $6 \mathrm{~min} 30 \mathrm{sec}$

3. SECOND SI THINNING OXIDATION (blanket) $1000^{\circ} \mathrm{C} 20 \mathrm{~min}$ dry, $\sim 23 \mathrm{~min}$ wet (based on first oxidation)

target oxide thickness: $224 \mathrm{~nm}$ target Si removal: $98 \mathrm{~nm}$

a) Oxidation tube temperature $1000^{\circ} \mathrm{C}$

5 min preheat

2 " every 6 sec push

20 min oxidation

29 min oxidation

5 min anneal

2 " every 15 sec pull

$10 \mathrm{~min} \mathrm{cool}$
$\mathrm{O}_{2}$

$\mathrm{O}_{2}$

$\operatorname{dry} \mathrm{O}_{2}$

$\mathrm{O}_{2}+$ pyrogenic $\mathrm{H}_{2} \mathrm{O}$

$\mathrm{N}_{2}$

$\mathrm{N}_{2}$

$\mathrm{N}_{2}$

target thickness:250 nm

thickness measured on test wafer: $236.2 \mathrm{~nm}$

3.1 TOP UP OXIDATION FROM $236.2 \mathrm{~nm}$ TO $244 \mathrm{~nm}-246 \mathrm{~nm}, 100{ }^{\circ} \mathrm{C} 35 \mathrm{~min}$ dry

5 min preheat

2 " every 6 sec push

35 min oxidation
$\mathrm{O}_{2}$

$\mathrm{O}_{2}$

dry $\mathrm{O}_{2}$ 


$\begin{array}{ll}5 \text { min anneal } & \mathrm{N}_{2} \\ 2 " \text { every } 15 \mathrm{sec} \text { pull } & \mathrm{N}_{2} \\ 10 \text { min cool } & \mathrm{N}_{2}\end{array}$

\section{ETCH OXIDE FROM HALF THE WAFER}

Half \& Half P.E. $\quad$ Mask $1 / 2$ and $1 / 2$ mask

a) dehydration bake, apply, prebake, expose, develop, postbake, descum S1811 photoresist

b) remove oxide on half the wafer etch in buffered HF until oxide removed estimated etch time: actual etch time: $2 \mathrm{~min} 30 \mathrm{sec}$

c) strip PR in PlasmaPreen

\section{THIRD SI THINNING OXIDATION $1100{ }^{\circ} \mathrm{C} 10 \mathrm{~min}$ dry} target oxide thickness: $45 \mathrm{~nm}$ target Si removal: $20 \mathrm{~nm}$ include test wafer
a) RCA clean
b) Oxidation tube temperature $1100^{\circ} \mathrm{C}$

$\begin{array}{ll}5 \text { min preheat } & \mathrm{O}_{2} \\ 2 \text { " every } 6 \mathrm{sec} \text { push } & \mathrm{O}_{2} \\ 10 \text { min oxidation } & \text { dry } \mathrm{O}_{2}\end{array}$




$\begin{array}{ll}20 \text { min anneal } & \mathrm{N}_{2} \\ 2 " \text { every } 15 \mathrm{sec} \text { pull } & \mathrm{N}_{2} \\ 10 \text { min cool } & \mathrm{N}_{2}\end{array}$

target thickness: $45 \mathrm{~nm}$

thickness measured on test wafer: $45.5 \mathrm{~nm}$

\section{STRIP ALL OXIDE}

a) remove oxide

etch in $10 \%$ HF until oxide removed

estimated etch time:

actual etch times: $10 \mathrm{~min}$

7. PAD OXIDE GROWTH $1100^{\circ} \mathrm{C} 11 \mathrm{~min}$ dry $\mathrm{O}_{2}$

target oxide thickness: $50 \mathrm{~nm}$ target Si removal: $22 \mathrm{~nm}$ include test wafer

a) RCA clean

b) Oxidation tube temperature $1100^{\circ} \mathrm{C}$

5 min preheat $\quad \mathrm{O}_{2}$

2 " every 6 sec push $\quad \mathrm{O}_{2}$

11 min oxidation dry $\mathrm{O}_{2}$

20 min anneal $\quad \mathrm{N}_{2}$

2 " every $15 \mathrm{sec}$ pull $\mathrm{N}_{2}$

10 min cool $\quad \mathrm{N}_{2}$ 
target thickness: $50 \mathrm{~nm}$

thickness measured on test wafer: $52.5 \mathrm{~nm}$

\section{NITRIDE DEPOSITION $80 \mathrm{~nm}$}

include test wafer

LPCVD tube temperature: $820^{\circ} \mathrm{C}$

deposition time: $13 \mathrm{~min}$

target thickness: $80 \mathrm{~nm}$

9. SI THINNING PE (ETCH NITRIDE AND PAD OXIDE) Mask CU-296-01

a) dehydration bake, apply, prebake, expose, develop, postbake, descum S1811 photoresist

b) plasma etch nitride (Technics Planar Etch II)

power: $100 \mathrm{~W} \quad$ source gas: freon $/ 5 \% \mathrm{O}_{2}$

pressure: 0.3 Torr

estimated etch time: $1 \mathrm{~min} 50 \mathrm{sec}$

actual etch times:

c) remove pad oxide

etch in buffered HF until

oxide removed from device wells

10. FOURTH SI THINNING OXIDATION $1100^{\circ} \mathrm{C}, 80 \mathrm{~min}$ dry target oxide thickness: $147 \mathrm{~nm}$ target Si removal: $64 \mathrm{~nm}$

a) RCA clean

b) Oxidation tube temperature $1100^{\circ} \mathrm{C}$

5 min preheat $\quad \mathrm{O}_{2}$ 


$\begin{array}{ll}2 \text { " every } 6 \text { sec push } & \mathrm{O}_{2} \\ 80 \text { min oxidation } & \text { dry } \mathrm{O}_{2} \\ 40 \text { min anneal } & \mathrm{N}_{2} \\ 2 \text { " every } 15 \text { sec pull } & \mathrm{N}_{2} \\ 10 \text { min cool } & \mathrm{N}_{2}\end{array}$

\section{NITRIDE / OXIDE STRIP}

a) remove converted nitride etch in $10 \%$ HF until oxide removed from top of nitride actual etch time $-30 \mathrm{sec}$

b) plasma etch nitride (Technics Planar Etch II)

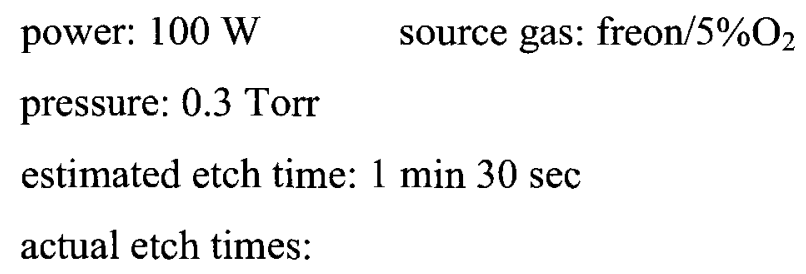

c) remove all oxide etch in buffered HF until oxide removed from device wells estimated etch time: $40 \mathrm{sec}$ actual etch times: $1 \mathrm{~min} 30 \mathrm{sec}$

12. SCREEN OXIDATION $1000^{\circ} \mathrm{C} 12 \mathrm{~min}$ dry target oxide thickness: $10 \mathrm{~nm}$

a) RCA clean

b) Oxidation tube temperature $1100^{\circ} \mathrm{C}$

$$
5 \text { min preheat } \quad \mathrm{O}_{2}
$$




$\begin{array}{ll}2 \text { " every 6 sec push } & \mathrm{O}_{2} \\ 5 \text { min oxidation } & \text { dry } \mathrm{O}_{2} \\ 40 \text { min anneal } & \mathrm{N}_{2} \\ 2 " \text { every } 15 \mathrm{sec} \text { pull } & \mathrm{N}_{2} \\ 10 \text { min cool } & \mathrm{N}_{2}\end{array}$

\section{3. $\mathrm{N}+$ ARSENIC IMPLANT ENERGY $50 \mathrm{keV}$}

Ship to Kroko implant services

HS1 :energy $50 \mathrm{keV}$, dose $1 \mathrm{e} 15 \mathrm{~cm}^{-2}$

HS2: energy $50 \mathrm{keV}$ dose $1 \mathrm{e} 14 \mathrm{~cm}^{-2}$

\section{IMPLANT ANNEAL $1000^{\circ} \mathrm{C} 10 \mathrm{~min}$}

tube temperature $: 1000{ }^{\circ} \mathrm{C}$
a) RCA clean
b) anneal

$\begin{array}{ll}5 \text { min preheat } & \mathrm{N}_{2} \\ 2 " \text { every 6 sec push } & \mathrm{N}_{2} \\ 10 \text { min anneal } & \mathrm{N}_{2} \\ 2 " \text { every 15 sec pull } & \mathrm{N}_{2} \\ 10 \text { min cool } & \mathrm{N}_{2}\end{array}$

\section{EMITTER DIELECTRIC PRECLEAN AND DEPOSITION $\sim 100 \mathrm{~nm}$}

done at Mc master university, Hamilton

After dielectric deposition samples were annealed Bruce 8 stack tube 6:

25 min@900 ${ }^{\circ} \mathrm{C}$ then $60 \min @ 800^{\circ} \mathrm{C}$. 
16. LPCVD CAP NITRIDE DEPOSITION

Nitride deposition $80 \mathrm{~nm}$

include test wafer

LPCVD tube temperature: $820^{\circ} \mathrm{C}$

deposition time: $5 \mathrm{~min} 50 \mathrm{sec}$

target thickness: $30 \mathrm{~nm}$

actual thickness $32.6 \mathrm{~nm}$

\section{LOTOX DEPOSITION $1 \mu \mathrm{m}$ (LPCVD FIELD OXIDE)}

include test wafer

tube temperature $410^{\circ} \mathrm{C}$

target thickness $1 \mu \mathrm{m}$

actual thickness $1.04 \mu \mathrm{m}$

\section{FIELD OXIDE PE (ETCH THROUGH LOTOX TO EXPOSE NITRIDE)}

\section{Mask CU 296-02}

a) Plasma preen, apply, prebake, expose, develop, postbake, descum S1811 photoresist

b) Lotox etch $\sim 5$ min BOE (buffered oxide etchant ( $7: 1$ )

c) strip PR in acetone/IPA/DI water + Plasma Preen

\section{ITO DEPOSITION (CONDUCTIVE TOP ELECTRODE)}

$230 \mathrm{~nm}$ thick ITO reactive sputtering (Semicore SC 943 inline sputtering system)

Base pressure $=2.4 \times 10^{-7}$ Torr, Process pressure $=5$ mTorr, Gas Argon, Recipe:

ITO1pass, scan speed $12.63 \mathrm{~cm} / \mathrm{min}$. 
20. ITO/EMITTER PE (patterns ITO and underlying emitter dielectric) Mask CU 296-03

a)dehydration bake, apply, prebake, expose, develop, postbake, descum S1811 photoresist

patterned by wet etching in $\mathrm{HCl} / \mathrm{HNO}_{3}$. ITO etch in Aqua Regia

Pour $200 \mathrm{~mL}$ of DI water into beaker and heat to $45^{\circ} \mathrm{C}$ (using the thermocouple feedback to control the hotplate).

In a separate beaker dispense $160 \mathrm{~mL}$ of hydrochloric acid, followed by $40 \mathrm{~mL}$ of nitric acid. Allow the solution to age for $90 \mathrm{~s}$, it should turn yellow.

Carefully add the mixture to the $200 \mathrm{~mL}$ of water. The solution will heat up. Maintain a temperature of $45^{\circ} \mathrm{C}$ unless otherwise specified.

Slowly insert wafer holder into the solution and allow to etch as instructed in FabFlow.

\section{WATCHPOINT: Look for uniform removal of ITO across the wafers}

Upon completion, remove wafers from the solution and rinse in flowing DI water. Inspect wafer under microscope for complete removal of ITO. In the event of incomplete etching, repeat process.

PR strip - acetone/IPA/DI water

\section{CONTACT PE (etch through dielectric stack to expose Si for contacts)} Mask CU 296-04

a)dehydration bake, apply, prebake, expose, develop, postbake, descum S1811 photoresist 
5 min BOE (buffered oxide etchant (7:1) etches through LOTOX $1 \mu \mathrm{m}$

$2 \mathrm{~min} 40 \mathrm{sec}$ Technics RF plasma etching, CF4/O2 gas, to etch through $30 \mathrm{~nm}$ nitride

$1 \mathrm{~min} 15 \mathrm{sec} \mathrm{BOE}$ - to etch through emitter dielectric oxide $(100 \mathrm{~nm})$

PR strip - acetone/IPA/DI water. Plasmapreen $5 \mathrm{~min}+5 \mathrm{~min}$.

22. METAL PE Mask CU 296-05

a) dehydration bake, apply, prebake, expose, develop, postbake, descum, LOR 10B, S1811 photoresist

\section{AL DEPOSITION AND LIFT-OFF}

$1 \mu \mathrm{m}$ thick Al layer was deposited by e-beam evaporation (Balzers)

Base pressure $-2 \times 10-6$ torr, substrate at ambient temp. and patterned by lift-off to provide contact to both the ITO and doped Si film. 


\section{REFERENCES}

[1] J. Y. Tsao, M.E Coltrin, M.H. Crawford, J.A. Simmons, "Solid-State Lighting: An Integrated Human Factors, Technology, and Economic Perspective," Proceedings of the IEEE, vol.98, no.7, pp.1162-1179, July 2010.

[2] I. L. Azevedo, M. G. Morgan and F. Morgan, "The Transition to Solid-State Lighting", Proceedings of the IEEE, pp 481 - 510, March 2009.

[3] A. R. Duggal, "OLEDs for Solid State Lighting", Lasers and Electro-Optics, pp 1-2, May 2008.

[4] M.S. Shur, R. Zukauskas, "Solid-State Lighting: Toward Superior Illumination", Proceedings of the IEEE, vol. 93, Issue: 10, pp. 1691 - 1703, Oct. 2005.

[5] S.C. Allen, Student Member, IEEE, and A.J. Steckl, Fellow, "ELiXIR—Solid-State Luminaire with Enhanced Light Extraction by Internal Reflection", IEEE JOURNAL OF DISPLAY TECHNOLOGY, vol. 3, NO. 2, June. 2007.

[6] A. Bierman "LEDs: From indicators to illumination?" Lighting Futures 3(4), Rensselaer Polytechnic Institute, 1998, http://www.Irc.rpi.edu/programs/Futures/LFLEDs/index.asp.

[7] Group IV Semiconductor, The Business Case. [www.groupivsemi.com]. http://www.groupivsemi.com/businesscase.html 
[8] B. Jalali, S. Fathpour, "Silicon Photonics," Lightwave Technology, Journal of, vol.24, no.12, pp.4600-4615, Dec. 2006.

[9] D.J. Lockwood, Light emission in silicon: from physics to devices, Academic Press, San Diego, 1998.

[10] C.Lin, M.Chen, S. Chang, P. Chung, E. Liang, T. Su, , C. W. Liu, "Electroluminescence at silicon band gap energy from mechanically pressed indium-tinoxide/Si contact," Applied Physics Letters, vol.78, no.13, pp.1808-1810, Mar 2001.

[11] S.Tsuji, J. Buus and Y. Luo, Proceedings of SPIE - The International Society for Optical Engineering, vol. 6020, article 60201R, 2005.

[12] G.T. Reed and A.P. Knights, Silicon Photonics: an introduction, Wiley, 2004.

[13] A.W. Bogalecki and M. Du Plessis, Proceedings of SPIE - The International Society for Optical Engineering, Optoelectronic Integrated Circuits XII, vol.7605, article 76050B, 2010.

[14] H.S. Saini, T.W. MacElwee, A. Rankin ,J. Wojcik, A.M. Miles, N.G. Tarr and P. Mascher " SOI Back reflector for Tb doped Oxide Electroluminescent Devices", Silicon Photonics, Ottawa, May 2011.

[16] R. Hull, "Properties of crystalline silicon", The Institution of Electrical Engineers, London, 2006.

[17] A. Luque, S. Hegedus, Handbook Of Photovoltaic Science And Engineering, John Wiley and Sons, Chichester, U.K, 2011.

[18] L. Pavesi, S. V. Gaponenko, L.D. Negro, Towards the first silicon laser, Springer, 2003. 
[19] Y. Zhizhong, A. Anopchenko, N. Daldosso, R. Guider, D . Navarro-Urrios, A. Pitanti, R. Spano, L. Pavesi, "Silicon Nanocrystals as an Enabling Material for Silicon Photonics," Proceedings of the IEEE, vol.97, no.7, pp.1250-1268, July 2009.

[20] D. J. Lockwood, op. cit., Ch1.

[21] L. Bergman, J.L. Morrison, C. Xiang-Bai; J. Huso, H. Hoeck, T. Zheleva, "Bandgap Engineering of UV-Luminescent Nanomaterials," Semiconductor Device Research Symposium, 2005 International, pp.197-198, 7-9 Dec. 2005.

[22] S. Lombardo, S. U. Campisano, G. N. van den Hoven, A. Polman, "Erbium in oxygen-doped silicon: Electroluminescence," Journal of Applied Physics, vol.77, no.12, pp.6504-6510, Jun 1995.

[23] S.S. Iyer, Y.-H. Xie ,"Light Emission From Silicon", Science, 260, 40 (1993).

[24] X. D. Pi, O. H. Y. Zalloum, J . Wojcik, A. P. Knights, P. Mascher, A. D. W .Todd, and P. J. Simpson, "Formation and oxidation of Si nano-clusters in Er-doped Si-rich SiOx", Journal of. Appl. Phys., 97, (2005) 096108.

[25] X. D. Pi, O. H. Y. Zalloum, T. Roschuk, J. Wojcik, A. P. Knights, P. Mascher, and P J Simpson, "Light Emission from Si nanoclusters formed at low temperatures", Appl. Phys. Lett., 88, (2006).

[26] D. Leong, M. Harry, K. J. Reeson, and K. P. Homewood, "A silicon/iron-disilicide light-emitting diode operating at a wavelength of 1.5 um", Nature, vol. 387,pp. 686-688, 1997. 
[27] C. Li, T. Suemasu, and F. Hasegawa,"Room-temperature electroluminescence of a Si-based $\mathrm{p}-\mathrm{i}-\mathrm{n}$ diode with $\beta-\mathrm{FeSi} 2$ particles embedded in the intrinsic silicon", Journal of . Appl. Phys., vol. 97, p. 043529, 2005.

[28] H. Zimmermann, Integrated Silicon Optoelectronics, Springer, ch 9, p 247, 2009.

[29] N. Daldosso, D. Navarro-Urrios, M. Melchiorri, C. Garcia, P. Pellegrino, B. Garrido, C. Sada, G. Battaglin, F. Gourbilleau, R. Rizk, L. Pavesi, "Er-Coupled Si Nanocluster Waveguide," Selected Topics in Quantum Electronics, IEEE Journal of, vol.12, no.6, pp.1607-1617, Nov.-Dec. 2006.

[30] D.J. Lockwood, op. cit., ch 4, p 113.

[31] T.W. MacElwee, S.E. Hill, S. Campbell, D. Ducharme, B. A. Rioux, and I.D. Calder, M. Flynn, J. Wojcik, S. Gujrathi, and P. Mascher, "Bright green visible electroluminescence from rare earth doped silicon rich SiOx", 3rd IEEE International Conference on Group IV Photonics, 2006.

[32] G. T. Reed, op. cit.

[33] Jean-Pierre Colinge, Silicon-on-insulator technology: materials to VLSI

[34] S. S. Iyer, A. J. Auberton-Hervé, Silicon wafer bonding technology: for VLSI and MEMS applications, Institution of Electrical Engineers.

[35] A. Thelen, Design of optical interference coatings, New York: McGraw-Hill, 1989.

[36] H. Angus Macleod Boca Raton, Thin-film optical filters, FL: CRC Press/Taylor \& Francis, 2010

[37] U. S. Inan, A.S. Inan, Electromagnetic Waves, Prentice Hall , NJ,2000 .

[38] E.D. Palik, Handbook of Optical Constants of Solids, Academic Press, Boston, 1985. 
[39] T.W. MacElwee, op. cit.

[40] P. E. Schmid, "Optical absorption in heavily doped silicon", Phys. Rev. B., vol. 23, p. $5531,1981$.

[41]S.M. Sze, Physics of Semiconductor Devices, Wiley, 1981.

[42] Synopsys Inc., Taurus TSUPREM-4 User Guide, 2005.

[43] J.D. Plummer, M. D. Deal, P. B. Griffin, Silicon VLSI technology: fundamentals, practice and modeling, Prentice Hall, 2000.

[45] J. M. Sun, W. Skorupa, T. Dekorsy, M. Helm, L. Rebohle, T. Gebel, "Efficient ultraviolet electroluminescence from a Gd-implanted silicon metal-oxide-semiconductor device," Applied Physics Letters, vol.85, no.16, pp.3387-3389, Oct 2004. [44] M.E. Castagna, S. Coffa, M. Monaco, A. Muscara, L. Caristia, S. Lorenti, A. Messina, "High efficiency light emitting devices in silicon", Materials Science and Engineering, vol. 105, pp. 83-90, Issues 1-3, 15 December 2003.

[46] M. Helm, J.M. Sun, J. Potfajova, T. Dekorsy, B. Schmidt, W. Skorupa, "Efficient silicon based light emitters", Microelectronics Journal, vol. 36, pp.957-962, Issue 11, November 2005. 